IZA DP No. 9785

Time Aggregation and State Dependence in Welfare Receipt

Manudeep Bhuller

Christian N. Brinch

Sebastian Königs

March 2016 


\title{
Time Aggregation and State Dependence in Welfare Receipt
}

\author{
Manudeep Bhuller \\ University of Chicago, Statistics Norway (SSB)
}

and IZA

Christian N. Brinch

BI Norwegian Business School

Sebastian Königs

$O E C D$ and IZA

Discussion Paper No. 9785
March 2016

IZA

P.O. Box 7240

53072 Bonn

Germany

Phone: +49-228-3894-0

Fax: +49-228-3894-180

E-mail: iza@iza.org

Any opinions expressed here are those of the author(s) and not those of IZA. Research published in this series may include views on policy, but the institute itself takes no institutional policy positions. The IZA research network is committed to the IZA Guiding Principles of Research Integrity.

The Institute for the Study of Labor (IZA) in Bonn is a local and virtual international research center and a place of communication between science, politics and business. IZA is an independent nonprofit organization supported by Deutsche Post Foundation. The center is associated with the University of Bonn and offers a stimulating research environment through its international network, workshops and conferences, data service, project support, research visits and doctoral program. IZA engages in (i) original and internationally competitive research in all fields of labor economics, (ii) development of policy concepts, and (iii) dissemination of research results and concepts to the interested public.

IZA Discussion Papers often represent preliminary work and are circulated to encourage discussion. Citation of such a paper should account for its provisional character. A revised version may be available directly from the author. 


\section{ABSTRACT}

\section{Time Aggregation and State Dependence in Welfare Receipt ${ }^{\star}$}

Dynamic discrete-choice models are an important tool in studies of state dependence in benefit receipt. A common assumption of such models is that benefit receipt sequences follow a conditional Markov process. This property has implications for how estimated periodto-period benefit transition probabilities should relate when receipt processes are aggregated over time. This paper assesses whether the conditional Markov property holds in welfare benefit receipt dynamics in Norway using high-quality monthly data from administrative records. We find that the standard conditional Markov model is seriously misspecified. Estimated state dependence is affected substantially by the chosen time unit of analysis, with the average treatment effect of past benefit receipt increasing with the level of aggregation. The model can be improved considerably by permitting richer types of benefit dynamics: We find strong evidence for both duration and occurrence dependence in benefit receipt. Allowing for heterogeneity in the entry and persistence processes, we find important disparities in the effects of observed and persistent unobserved characteristics. Based on our preferred model, the month-to-month persistence probability in benefit receipt for a first-time entrant is 37 percentage points higher than the entry rate of an individual without previous benefit receipt. Over a 12-month period, this corresponds to an average treatment effect of 5 percentage points.

JEL Classification: I38, J60, J64, C23, C41

Keywords: time aggregation, Markov property, state dependence, welfare dynamics

Corresponding author:

Manudeep Bhuller

Department of Economics

University of Chicago

1126 E. $59^{\text {th }}$ Street

Chicago, IL 60637

USA

E-mail: bhuller@uchicago.edu

\footnotetext{
* This is the pre-peer-review version of a paper forthcoming in The Economic Journal, doi: 10.1111/ecoj.12366. We thank Rolf Aaberge, Wiji Arulampalam, Tony Atkinson, Steve Bond, Stéphane Carcillo, Ian Crawford, Herwig Immervoll, Stephen Jenkins, and Arvid Raknerud for their comments, which helped to greatly improve this paper. We are grateful for the questions and suggestions received from seminar participants at the University of Oxford, the IZA/OECD/World Bank conference on Social Safety Nets in Paris, the IAB conference on Dynamics of Low Wage, Low Pay and Transfer Receipt in Nuremberg, the Institute for Social Research in Oslo, and the 2014 Annual Conference of the Royal Economic Society in Manchester. Financial support from the Research Council of Norway (194339), the European Union as part of the joint OECD/EU project "Multi-country Database on Benefit Recipients and Analysis of Recipiency Patterns" (2010-13) and the INET grant INO1200010 by the Institute for New Economic Thinking at the Oxford Martin School is gratefully acknowledged. While carrying out this research, Brinch has been associated with the centre of Equality, Social Organization, and Performance (ESOP) at the Department of Economics at the University of Oslo. ESOP is supported by the Research Council of Norway. The usual disclaimer applies. In particular, the opinions expressed and arguments employed herein are solely those of the authors and do not necessarily reflect the official views of Statistics Norway, the OECD, the European Union or OECD or EU member countries.
} 


\section{Introduction}

An established finding in the literature on welfare benefit dynamics is that rates of persistence in individuals' benefit receipt from one period to the next are very high. Given typically low entry rates into benefit receipt, a main focus of recent studies has therefore been to assess the driving forces of this 'state dependence'. ${ }^{1}$ Heckman $(1978,1981 \mathrm{a})$ distinguishes two sources of state dependence. First, individuals differ in terms of their personal characteristics. Persistent individual characteristics such as low education or health problems that raise the probability of benefit receipt will induce persistence in welfare. A failure to appropriately control for persistent heterogeneity in such characteristics across individuals will lead to spurious state dependence. Second, past benefit receipt might itself affect the probability of receiving benefits today. For instance, previous receipt of welfare benefit payments might reduce information costs or the perceived stigma from receiving benefit payments and thus make future benefit receipt more likely. Alternatively, potential employers might interpret past benefit receipt as a negative signal about an applicant's unobserved labour productivity, which would make self-sufficiency less likely. This direct effect of past benefit receipt on the probability of future benefit receipt is referred to as true, genuine or structural state dependence.

Two related approaches have been employed in the empirical literature to study the sources of persistence in labour market histories. Duration models analyse the processes leading up to an exit from a labour market state, for instance welfare benefit receipt. Persistence is typically introduced by allowing the exit rate from the labour market state to depend not only on individual characteristics but also on the length of current or past spells in that state. Applications of such models in labour economics typically use data collected at short, discrete time intervals such as weeks or months and thus require access to detailed event-history data. Dynamic discrete-choice models have been a popular alternative in cases where weekly or even monthly data on benefit receipt are not available. These models are based on a single specification for both entry and persistence in the labour market state, where the probability of being in that state is allowed to depend on the individual's state in the previous period. Estimation of such models requires data to also extend to periods in which the individual is outside the state being modelled. The presence of unobserved heterogeneity poses a formidable threat to identification in both duration models and dynamic discrete-choice models. For both types of models, econometric methods however exist to account for persistent unobserved heterogeneity and thereby obtain consistent estimates of structural state dependence (Van den Berg, 2001; Heckman \& Navarro, 2007).

The recent work on welfare benefit dynamics has primarily relied on estimation of dynamic discrete-choice models to study state dependence in benefit receipt. ${ }^{2}$ Due to the limited availability of individual-level data on welfare benefit receipt at shorter observation intervals much

\footnotetext{
${ }^{1}$ Our calculations for Norway for instance show that month-to-month entry rates of working-age individuals to means-tested Social Economic Assistance were around or below $0.5 \%$ for most of the last two decades whereas persistence rates in benefit receipt averaged around $75 \%$ (see Figure 1).

${ }^{2}$ Similar models have also been estimated to study the dynamics of employment (Heckman, 1981a; Hyslop, 1999), unemployment (Arulampalam, Booth \& Taylor, 2000; Gregg, 2001; Biewen \& Steffes, 2010), or low-income or poverty (Stewart \& Swaffield, 1999; Cappellari \& Jenkins, 2004; Stewart, 2007; Cappellari \& Jenkins, 2008b; Biewen, 2009). More recent studies analyse transitions between multiple labour market states using dynamic multinomial-choice models (Uhlendorff, 2006; Prowse, 2012).
} 
of the evidence on state dependence in welfare benefit receipt is based on annual data that come either from administrative sources (see Hansen \& Lofstrom $(2008,2011)$ or Andrén \& Andrén (2013) for Sweden) or from household survey data (Cappellari \& Jenkins (2009) for Britain, Riphahn \& Wunder (2013), Wunder \& Riphahn (2014) and Königs (2014) for Germany, and Hansen, Lofstrom, Liu \& Zhang (2014) for Canada). Notable exceptions are two U.S. studies based on monthly administrative data from California (Chay, Hoynes \& Hyslop, 1999) and four-monthly survey data (Chay \& Hyslop, 2014), and a study of transitions between Australian benefit programmes based on quarterly data (Gong, 2004). A small number of studies have moreover used monthly data and an event-history framework to analyse welfare spell durations for the U.S. (Blank, 1989; Sandefur \& Cook, 1998), Norway (Dahl \& Lorentzen, 2003b), Sweden (Bäckman \& Bergmark, 2011; Mood, 2013), and Germany (Schels, 2013), each finding evidence for duration dependence in welfare benefit receipt.

A key assumption made in dynamic discrete-choice models is that benefit dynamics follow a Markov process: conditional on observed and unobserved individual characteristics the first lag of the dependent variable is sufficient for predicting the outcome. Higher-order lags are assumed not to add any predictive power to the model..$^{3}$ This conditional Markov property has important implications for the aggregation of dynamic processes over time. If a model exhibits the Markov property at the monthly level, this property carries through to the annual level when the dynamic process is aggregated over time. There will hence be a one-to-one correspondence between the benefit transition probabilities in these two specifications. If the assumed Markov property does not hold, the results obtained from such an analysis - notably the estimated degree of state dependence - will be affected by the choice of the observation interval. As indicated above, the choice of the level of aggregation in previous analyses of welfare benefit dynamics appears in practice to be determined primarily by the availability of suitable micro-level panel data rather than to be justified by theoretical considerations. To our knowledge, there exists no study however that systematically tests the validity of the Markov assumption in an analysis of benefit receipt dynamics and that assesses the implications of a violation of this assumption on the level of estimated structural state dependence. ${ }^{4}$

In this paper, we develop a framework for evaluating whether the conditional Markov assumption is reasonable in such models of labour market dynamics. We exploit the property that if a model satisfies the conditional Markov assumption at a given level of time aggregation this characteristic will hold also at higher levels of aggregation. A well-specified model of monthly labour market dynamics for instance should thus give 12-month-ahead predictions that

\footnotetext{
${ }^{3}$ Two exceptions are the studies by Chay et al. (1999), who specify a second-order Markov process using monthly administrative data for California, and Andrén \& Andrén (2013), who specify a third-order Markov process using annual administrative data for Sweden.

${ }^{4}$ The only analysis of time aggregation problems in dynamic discrete-choice models that we are aware of is provided by Chay et al. (1999). They estimate dynamic conditional logit models at the monthly, quarterly and biennial level to study welfare receipt dynamics in the U.S. Comparing the size of coefficient estimates and the implied predicted shares of receipt sequences with state dependence across specifications they conclude that aggregating data leads to an attenuation in the estimated level of state dependence. It is not obvious however whether estimates of state dependence from such models can be expected to be the same in receipt sequences measured at different observation intervals (see discussion in Section 3). A related literature discusses problems of time aggregation in dynamic time-series models (see e.g. Engle \& Liu (1972); Tiao \& Wei (1976); Mercenier \& Michel (1994)) or the estimation of continuous time event-history models with discrete data (see e.g. Petersen \& Koput (1992); Røed \& Zhang (2002) for Monte Carlo evidence and Bergström \& Edin (1992) using actual data.)
} 
are comparable to the year-to-year predictions derived from a corresponding model of annual labour market dynamics. The virtue of this exercise is that it provides a test of substance rather than of statistical significance as it could easily be obtained by including higher-order lags in a Markov model. Any failure of the test indicates a non-robustness of results to the choice of time unit and is therefore evidence of model misspecification.

We apply this test to assess the validity of the conditional Markov assumption for a standard dynamic random-effects probit model of welfare benefit receipt in Norway. Using administrative data for six cohorts of young adults over the years 1993-2008, we find that estimates of state dependence derived from a standard first-order Markov model at the monthly, annual and biennial level fail to relate the way that we should expect if the model were well-specified. The degree of estimated state dependence is found to increase with the level of time aggregation. This is the case irrespective of whether we measure annual benefit receipt once during the calendar year ('point-in-time' definition) or whether we account for benefit receipt at any time during the year ('benefit year' definition). Both approaches have been frequently used in the existing work on welfare benefit dynamics. The magnitude of estimated state dependence at the annual level moreover differs substantially between these two approaches.

In the second part of our analysis, we extend the dynamic random-effects probit model to permit richer types of benefit dynamics. We specify a more general dynamic random-coefficients probit model that allows the processes driving entries into and persistence in benefit receipt to vary with observable and unobservable characteristics. Moreover, we abandon the first-order Markov assumption by allowing for duration and occurrence dependence along the lines proposed by Heckman \& Borjas (1980). We find evidence of sizeable duration dependence in both entries into and persistence in benefit receipt as well as a significant effect of previous episodes of benefit receipt on welfare entry rates. Predicted persistence rates for individuals who first entered benefit receipt in the last period are 37 percentage points higher than entry rates for individuals who never touched benefits. This translates into a predicted average treatment effect of benefit receipt 12 months ago on the likelihood of benefit receipt today of 5 percentage points. A simple specification test indicates that the model provides a substantial improvement over the Markov models in terms of its time aggregation properties. However, even our most complex model of benefit dynamics does not fully succeed at replicating the true data-generating process.

The remainder of this paper is structured as follows: In the next section, we provide a short introduction to the welfare benefit system in Norway and present the data used in our study. Section 3 gives a brief outline of the standard Markov models employed in the existing literature and relates the implied transition probabilities for different levels of time aggregation. Section 4 provides empirical evidence on the performance of a first-order Markov model of welfare benefit dynamics in Norway. In Section 5, we present results from the dynamic random-coefficient probit model that allows for heterogeneity in entries and persistence in benefit receipt and duration and occurrence dependence and examine the time aggregation properties of this model. Section 6 concludes. 


\section{Institutional Background and Data}

The primary welfare benefit in Norway is Social Economic Assistance (SEA, Økonomisk sosialhjelp), which is regulated by the Social Services Act (Loven om sosiale tjenester). ${ }^{5}$ It guarantees a minimum income to all individuals who are unable to fully cover living expenses through own means, for instance through earnings, savings, social insurance benefits or payments from other minimum-income benefit programmes. SEA is means-tested and total household income is considered in the eligibility test. ${ }^{6}$ SEA benefits are explicitly designed to provide temporary income support, however the maximum possible duration of benefit payments is in principle unlimited. The minimum period of benefit receipt is typically one calendar month.
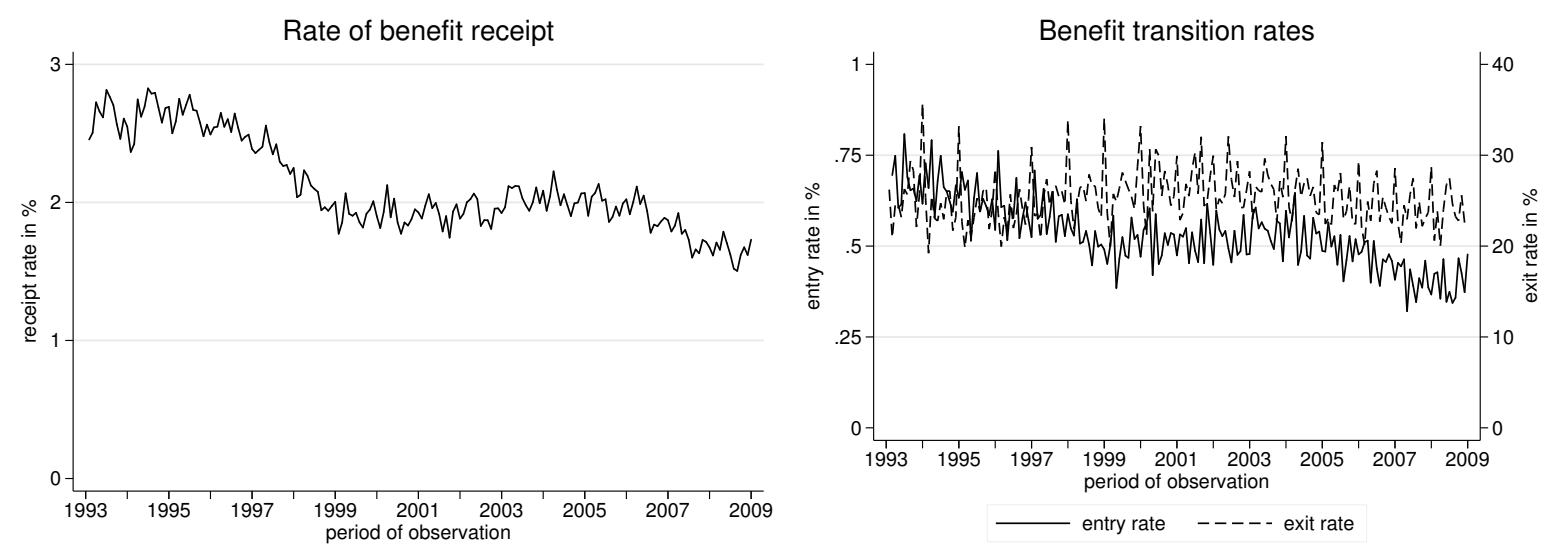

Note: Calculations based on a $10 \%$ random sample from the working-age population (aged 25-59 years). The benefit receipt rate gives the number of individuals in a benefit-receiving household as a share of the total workingage population. The entry rate is calculated as the number of individuals who receive benefits in period $t$ but not in period $t$ - 1 divided by the number of benefit recipients in period $t$ - 1 . Similarly, the exit rate is calculated as the number of individuals who do not receive benefits in period $t$ but received benefits in $t-1$ as a share of all benefit recipients in $t$-1. Source: FD-Trygd, January 1993 to December 2008.

\section{Figure 1: Rate of benefit receipt and benefit transition rates}

Figure 1 presents first descriptive evidence on the dynamics of SEA benefit receipt in Norway for the period from January 1993 to December 2008. The left panel plots the development of the monthly rate of welfare benefit receipt over the observation period. We see that the frequency of benefit receipt in Norway is low and declines from around 2.5\% in 1993 to just above $1.5 \%$ in 2008. The right panel of Figure 1 shows that this fall results primarily from a slight decline in entry rates into benefit receipt from just above $0.5 \%$ in the mid-1990s to below $0.5 \%$ in the $2000 \mathrm{~s}$. Month-to-month exit rates from benefit receipt are relatively stable over time around 20-30\%.

\footnotetext{
${ }^{5}$ Other means-tested income-support programmes in Norway are the Transitional Allowance (Overgangsstønad for enslige forsørgere) paid to needy single parents and the Housing Allowance (Bostøtte) for low-income households. We restrict our attention to the dynamics of SEA benefit receipt. For earlier analyses of welfare benefit dynamics in Norway, see Dahl \& Lorentzen (2003a,b), Lorentzen \& Dahl (2005), Hansen (2009) and Lorentzen (2010).

${ }^{6}$ Generosity of SEA benefits as well as the administration of payments is largely left to the discretion of the 430 Norwegian municipalities. The municipal governments determine so-called social assistance benefit norms as guidelines for the level of monthly payments to be made to a 'standard' recipient. In practice, actual payments then depend on the caseworker's assessment of the applicant's needs. Since 2001, the central government additionally provides national social assistance norms that are updated annually and aim at equalizing benefit payments across municipalities. These norms are however not binding. The municipal benefit administration may impose behavioural conditions on the claimant.
} 
At an implied persistence rate in benefit receipt from one month to the next of about $70-80 \%$, 'raw' state dependence in benefit receipt - i.e. the difference between observed persistence and entry rates - is substantial.

For our analysis we use data from a range of administrative registers maintained by Statistics Norway that are matched to form a monthly panel for the years 1993 to 2008. The primary source of data is the social security event-history database FD-Trygd (ForløpsDatabasen-Trygd). It is a collection of longitudinal data sets that provide detailed information on spells of employment and benefit receipt from unemployment insurance and income-support programmes for the entire Norwegian population. These data were drawn from various registers maintained by the Norwegian Labour and Welfare Service (NAV, Nye Arbeids- og Velferdsetaten) and the Norwegian Tax Authority (Skatteetaten). We match these data with socio-demographic data from separate administrative registers maintained by Statistics Norway that provide information on sex, age, marital status, immigrant status, and the municipality of residence. Data on household composition come from the Central Population Register, data on educational attainment are taken from the Norwegian National Education Database.

The resulting panel data set has a few distinct advantages: First, the number of observations is extremely large. The data pertain to all legal residents in Norway irrespective of their employment or social security status. Every child born in Norway during the observation period is automatically added to the register and becomes part of the data set. The same applies to every individual that migrates to Norway to live or work in the country. Individuals only disappear from the data in case of emigration or death. Second, the length of our panel is exceptional. Records are updated monthly, such that we can observe individuals for up to 192 monthly waves (16 years). Third, the quality of the data is high. For every individual, a large number of personal characteristics are observed on a monthly basis. Personal and household identifiers allow us to link children to their parents to construct household-level variables. Being register-based, the data set moreover does not suffer from any unnatural attrition or non-response.

We construct the sample for our analysis by restricting the population data set to individuals who match a certain set of selection criteria: We limit our sample to individuals who turn 18 years of age in the month of January of the years 1993 to 1998. All individuals belonging to one of these six cohorts are then followed from the month in which they turn 18 for a period of up to eleven years. After those eleven years, they are dropped from the sample. Individuals may leave the sample before through emigration or death. We use the first twelve months of an individual's 132-month observation period to construct a benefit receipt history that we condition on in the more complex models presented in Section 5. The estimation sample hence follows each individuals for up to 10 years (120 months) from January in the year when an individual turns 19 to the December just before the 29's birthday.

The main motivation for using these non-standard sample selection criteria is to guarantee that we observe all individuals from the beginning of their 'welfare careers'. This will be the case as individuals in Norway are generally not entitled to receive welfare benefits before reaching the age of 18 years. From that age, needy individuals claim benefits for themselves even if they continue to live with their parents. By restricting the sample to individuals who turn 18 years in January during the first six years of our observation period, we make sure that we observe 
the first period of potential benefit receipt for each individual. ${ }^{7}$ By dropping individuals after 10 years we make sure that the resulting sample is weakly balanced. ${ }^{8}$ The population that results from these selection criteria consists of 30,899 individuals and 3,279,708 person-month observations. All estimation results presented in this paper were obtained from this population. ${ }^{9}$

An analysis of welfare benefit dynamics requires choices about the appropriate period and unit of observation. As outlined, existing analyses have typically been carried out based on annual data. Depending on the nature of these data, the approach typically used for defining the annual welfare benefit variable differed. Survey data usually provide information on benefit receipt at the time of interview. Where this is the case, researchers have usually opted for a 'point-in-time' approach by modelling benefit transitions from one annual interview to the next, implicitly assuming that the transition probabilities remain unaffected by whether an individual received any payments in between those dates (see Cappellari \& Jenkins (2009), Riphahn \& Wunder (2013), Königs (2014) and Wunder \& Riphahn (2014)). ${ }^{10}$ Administrative records by contrast often contain data on the total amount of benefits received during the calendar year but no information on the timing of receipt. Researchers working with such data have usually employed a 'benefit year' approach classifying an individual as recipient if a positive amount of benefits was received over the entire year (Hansen \& Lofstrom, 2008, 2011; Andrén \& Andrén, 2013; Hansen et al., 2014). We test both of these approaches and compare the results. Finally, as in other countries, welfare benefits in Norway are paid at the family level. We therefore follow the standard approach of setting the binary benefit receipt variable equal to one for an individual if any member living in the same household in the given period receives benefits, to then model benefit receipt dynamics at the individual level.

\section{Time aggregation in a conditional Markov model}

The standard tool in the empirical literature on the dynamics of welfare benefit receipt are dynamic discrete-choice models, which rely on the assumption that benefit receipt dynamics follow a conditional Markov process. An important implication of this Markov property is that for a monthly model that satisfies this property the property carries through to the annual level if the process is aggregated over time. If the assumed Markov property is not valid, estimation

\footnotetext{
${ }^{7}$ This is important because to test for occurrence dependence in benefit receipt in Section 5 , we need to be able to count the total number of benefit spells an individual has had. Since we lack information about any benefit receipt an individual might have had prior to the year 1993, we restrict the sample to individuals whom we observe since the beginning of their welfare careers.

${ }^{8}$ Consistency of our estimations - in particular of the approach we use to control for the endogeneity of initial conditions - requires that an individual's participation in the sample be unrelated to the outcome variable. This is arguably unproblematic in the case of administrative data. By dropping individuals after 10 years, we however avoid that earlier cohorts are observed for a longer period and thus at higher ages than the following cohorts. In constructing our weakly balanced panel we follow an approach used by Prowse (2012).

${ }^{9}$ The disadvantage of our selection procedure is that the resulting sample is no longer representative of the Norwegian working-age population. To illustrate that our main results hold for a more standard sample, we have replicated the most important parts of our analysis using a $5 \%$ random sample of all 25-59 year-olds. The results from this robustness check are presented in an earlier working paper (Bhuller, Brinch \& Königs, 2014, Appendix A.3, pp. 55-61) but are omitted from this article for the sake of brevity. Our main conclusions are not driven by the non-standard sample design.

${ }^{10}$ In an earlier version of their paper, Cappellari \& Jenkins (2008a) show that the estimated level of state dependence falls substantially once individuals with one continuous spell across both interview dates are dropped from the sample.
} 
results and in particular the degree of estimated state dependence will depend on the choice of time unit. This section introduces the dynamic random-effects probit (DREP) model, the standard model used for the analysis of welfare benefit dynamics, and shows how conditional transition probabilities derived from such a model can be aggregated over time.

\subsection{The dynamic random-effects probit model}

Let us define a binary outcome variable $y_{i t}$ such that for $y_{i t}=1$ individual $i$ is in welfare receipt in period $t$. We specify the model

$$
y_{i t}=\mathbb{1}\left\{\lambda y_{i t-1}+x_{i t-1}^{\prime} \beta+\alpha_{i}+\varepsilon_{i t}>0\right\} \quad \text { for } i=1, \ldots, N ; t=1, \ldots, T_{i},
$$

where individual $i$ 's benefit receipt status in period $t$ depends on the benefit receipt status in the previous period $y_{i t-1}$, a vector of $k$ observable characteristics $x_{i t-1}$, a time-invariant individual-specific error component $\alpha_{i}$ and a transitory shock $\varepsilon_{i t} .{ }^{11}$ Observables $x_{i t-1}$ may include individual and household characteristics, such as sex, age, education, family composition, and possibly partner characteristics. The individual-specific error term $\alpha_{i}$ enters additively in the indicator function and captures all unobserved determinants of welfare benefit receipt that are time-invariant for an individual over the observation period. Such factors may for instance include persistent unobserved labour market ability or an individual's attitudes towards receiving welfare benefits. Distributional assumptions for $\alpha_{i}$ are discussed further below. The transitory error term $\varepsilon_{i t}$ is assumed to be distributed standard normal, to be uncorrelated with both $\alpha_{i}$ and the regressors $y_{i t-1}$ and $x_{i t-1}$, and to be serially uncorrelated. ${ }^{12}$

We write the conditional probability of welfare benefit receipt as

$$
P\left(y_{i t}=1 \mid y_{i 0}, \ldots, y_{i t-1}, x_{i}, \alpha_{i}\right)=\Phi\left(\lambda y_{i t-1}+x_{i t-1}^{\prime} \beta+\alpha_{i}\right)
$$

where $x_{i}=\left(x_{i 0}^{\prime} \ldots x_{i T_{i}}^{\prime}\right)^{\prime}$ is a $k \times\left(T_{i}+1\right)$ vector of all $k$ covariates over the $T_{i}$ time periods plus the initial period and $\Phi(\cdot)$ is the standard normal cumulative distribution function.

The model described by Equations (1) and (2) rests on two crucial assumptions. First, we assume that the welfare dynamics are correctly described by a first-order Markov model. Thus, conditional on observed and unobserved characteristics and the first lag of the outcome variable $y_{i t-1}$, higher-order lags do not provide any additional explanatory power. Second, we require that the observed characteristics $x_{i}$ be strictly exogenous. Once we condition on the individual-specific unobserved effect $\alpha_{i}$ only the observable characteristics in period $t-1$ matter for determining $y_{i t}$. An impact of earlier values of $x_{i}$ on the dependent variable or feedback effects between the dependent variable and current or future values of $x_{i}$ are ruled out. ${ }^{13}$ Under

\footnotetext{
${ }^{11}$ Following Cappellari \& Jenkins (2009), we measure all time-varying observable characteristics in period $t$ 1 such that period- $t$ predictions of the outcome variable are based on period- $t-1$ values of the observables. A robustness check indicates that using current rather than lagged values of all observable characteristics matters little for the estimation results in both the monthly and the annual model.

${ }^{12}$ The inter-temporal correlation of the composite error $\alpha_{i}+\varepsilon_{i t}$ is thus assumed to be constant at $\rho=\frac{\sigma_{\alpha}^{2}}{1+\sigma_{\alpha}^{2}}$ for any two periods.

${ }^{13}$ Biewen (2009) provides evidence on such feedback effects in a joint model of poverty, employment, and household composition for Germany, where future employment status and household composition are allowed to depend on past poverty status. In our analysis we follow the standard approach in the literature on welfare benefit
} 
these conditions, we can interpret the coefficient of the lagged dependent variable $\lambda$ as measuring structural state dependence. The spurious state dependence induced by persistent unobserved heterogeneity is captured by the individual-specific effect $\alpha_{i}$.

A well-known difficulty with the model described in Equations (1) and (2) is that it suffers from an initial conditions problem. To construct a likelihood function, we need to integrate out the unobserved individual-specific error component $\alpha_{i}$. This requires specifying the relationship between $\alpha_{i}$ and the benefit receipt status in the initial period $y_{i 0}$, which cannot be assumed to be exogenous.

To address this problem, we follow the approach developed by Wooldridge (2005). He proposes specifying the density of $\alpha_{i}$ conditional on $y_{i 0}$ and $x_{i}$ as $\alpha_{i}=\gamma_{0}+\gamma_{1} y_{i 0}+x_{i}^{\prime} \gamma_{2}+a_{i}$, where the residual error term $\left(a_{i} \mid y_{i 0}, x_{i}\right) \sim \mathcal{N}\left(0, \sigma_{a}^{2}\right){ }^{14}$ This allows rewriting the joint density of $\left(y_{i 1} \ldots y_{i T}\right) \mid y_{i 0}, x_{i}$ as

$$
f\left(y_{i 1}, \ldots, y_{i T} \mid y_{i 0}, x_{i} ; \theta, \gamma\right)=\int \prod_{t=1}^{T} f\left(y_{i t} \mid y_{i t-1}, x_{i t-1}, \alpha_{i} ; \theta\right) g\left(\alpha_{i} \mid y_{i 0}, x_{i} ; \gamma\right) d \alpha_{i},
$$

where the coefficient vector $\theta=\left(\lambda \beta^{\prime}\right)^{\prime}$. Note that this approach also allows for a correlation of the individual-specific component $\alpha_{i}$ with the explanatory variables along the lines proposed by Chamberlain (1980). The residual error term $a_{i}$ is uncorrelated with the regressors $x_{i}, y_{i 0}$ and the transitory shock $\varepsilon_{i t}$. The joint density used for estimation can then be written as

$$
\begin{aligned}
\int & \prod_{t=1}^{T}\left\{\left[\Phi\left(\lambda y_{i t-1}+x_{i t-1}^{\prime} \beta+\gamma_{1} y_{i 0}+x_{i}^{\prime} \gamma_{2}+a_{i}\right)\right]^{y_{i t}}\right. \\
& {\left.\left[1-\Phi\left(\lambda y_{i t-1}+x_{i t-1}^{\prime} \beta+\gamma_{1} y_{i 0}+x_{i}^{\prime} \gamma_{2}+a_{i}\right)\right]^{\left(1-y_{i t}\right)}\right\}\left(\frac{1}{\sigma_{a}}\right) \phi\left(\frac{a}{\sigma_{a}}\right) d a . }
\end{aligned}
$$

This density is identical to the one of the standard random-effects probit model with the additional explanatory variables $y_{i 0}$ and $x_{i}$ added in each period. Parameter estimates for this model can thus be obtained through maximum likelihood estimation. In empirical practice, the vector of past and future values of all covariates $x_{i}$ is typically substituted for by the individual longitudinal averages of all time-varying observables $\bar{x}_{i}$ as in the correlated random-effects model introduced by Mundlak (1978). This is also what we do in our analysis. ${ }^{15}$

We estimate all specifications in the free software package GNU Octave using a mean- and variance-adaptive Gauss-Hermite quadrature approximation routine for likelihood evaluation and use a Newton-Raphson algorithm for maximization (Butler \& Moffitt, 1982; Rabe-Hesketh, Skrondal \& Pickles, 2005). ${ }^{16}$

\footnotetext{
receipt dynamics and assume no such feedback effects exist.

${ }^{14}$ An alternative, widely-used approach due to Heckman (1981b) accounts for the correlation between the initial condition $y_{i 0}$ and the individual-specific effect by specifying a distribution of $y_{i 0} \mid x_{i}, \alpha_{i}$ and by then estimating the joint distribution of $f\left(y_{i 0}, \ldots, y_{i T} \mid x_{i}, \alpha_{i} ; \theta\right)$. The two approaches have been shown to differ little in performance for panels of appropriate length (Arulampalam \& Stewart, 2009; Akay, 2012). The Wooldridge approach however has the advantage of being computationally simpler and of extending in a relatively straightforward way to settings with richer state dependence (see further discussion by Stewart (2007, p. 527)) and in Appendix A.1.

${ }^{15}$ As suggested by Rabe-Hesketh \& Skrondal (2013), we tested an alternative specification that controls for the initial values of the observable characteristics $x_{i 0}$ in addition to $\bar{x}_{i}$. We however find that this model extension gives nearly identical results.

${ }^{16}$ As a robustness check, we re-estimated the model using a Monte Carlo Expectation Maximization (MCEM)
} 


\subsection{Time aggregation in a dynamic random-effects probit model}

The type of conditional Markov model presented in the previous subsection has clear implications for how period-to-period benefit transition probabilities should aggregate over time. For a Markov process with

$$
P\left(y_{t}=1 \mid y_{0}, \ldots, y_{t-1}\right)=P\left(y_{t}=1 \mid y_{t-1}\right)
$$

it must also hold that

$$
P\left(y_{t+k}=1 \mid y_{0}, \ldots, y_{t-1}\right)=P\left(y_{t+k}=1 \mid y_{t-1}\right)
$$

for any positive integer $k$ (see for instance Taylor \& Karlin (1998, Section 3.1)). This implies that for a monthly observation interval, only the outcome in the current period is relevant for making 12-month-ahead predictions. A month-to-month Markov process can be re-written as a year-to-year Markov process where benefit receipt is measured every 12 months. Benefit transitions can be aggregated up from the monthly to the annual level, and there will be a oneto-one correspondence between the transition probabilities at the two levels of time aggregation. If, by contrast, monthly benefit dynamics follow a more complex pattern it is unlikely that the Markov property would hold once the data are aggregated to the annual level.

In empirical practice, the DREP model just presented is typically estimated based on annual data. Neither for the 'point-in-time' approach nor for the 'benefit year' approach mentioned in Section 2 it is however obvious from a theoretical point of view why the conditional Markov property should be satisfied at the annual level. While the minimum period of welfare benefit receipt varies between countries, it is usually much shorter than a year. One sufficient (though not necessary) condition for why the conditional Markov property may hold at the annual level is that benefit dynamics follow a conditional Markov process at the monthly level. Regardless of the underlying dynamic process at the monthly level, the Markov assumption at the annual level moreover implies that benefit receipt dynamics should continue to satisfy the Markov property if we further aggregate up the data to the biennial level.

The Markov assumption thus has testable implications for the relationship between the predicted transition probabilities at the monthly, annual and biennial level that allow us to empirically validate the standard model of benefit receipt dynamics at both the monthly and the annual level.

\subsubsection{Aggregating transition probabilities over time}

In a DREP model, there is a relatively easy analytical solution for how transition probabilities aggregate up over time. Using the results from Section 3.1, we define the conditional probability of entry into benefit receipt in a Wooldridge-type version of the model as

$$
p_{i t}^{01}\left(y_{i t-1}, y_{i 0}, x_{i}, a_{i}\right)=P\left(y_{i t}=1 \mid y_{i t-1}=0, y_{i 0}, x_{i}, a_{i}\right)=\Phi\left(x_{i t-1}^{\prime} \beta+\gamma_{1} y_{i 0}+\bar{x}_{i}^{\prime} \gamma_{2}+a_{i}\right)
$$

algorithm that gives simulation-based maximum likelihood estimates (Wei \& Tanner, 1990). The two routines gave nearly identical results. 
and the corresponding persistence probability as

$$
p_{i t}^{11}\left(y_{i t-1}, y_{i 0}, x_{i}, a_{i}\right)=P\left(y_{i t}=1 \mid y_{i t-1}=1, y_{i 0}, x_{i}, a_{i}\right)=\Phi\left(\lambda+x_{i t-1}^{\prime} \beta+\gamma_{1} y_{i 0}+\bar{x}_{i}^{\prime} \gamma_{2}+a_{i}\right)
$$

We construct a transition matrix based on these expressions as

$$
\mathcal{A}_{i t}\left(y_{i t-1}, y_{i 0}, x_{i}, a_{i}\right)=\left[\begin{array}{cc}
1-p_{i t}^{01} & p_{i t}^{01} \\
1-p_{i t}^{11} & p_{i t}^{11}
\end{array}\right],
$$

where the dependence on covariates and the random effect of the four transition probabilities is suppressed for notational ease. For a column vector of possible states in the previous period $z_{i t-1}$, we can write

$$
\underbrace{E\left[\begin{array}{c}
1-y_{i t} \\
y_{i t}
\end{array}\right]}_{E\left(z_{i t} \mid z_{i t-1}, y_{i 0}, x_{i}, a_{i}\right)}=\underbrace{\left[\begin{array}{cc}
1-p_{i t}^{01} & 1-p_{i t}^{11} \\
p_{i t}^{01} & p_{i t}^{11}
\end{array}\right]}_{\mathcal{A}_{i t}^{\prime}\left(y_{i t-1}, y_{i 0}, x_{i}, a_{i}\right)} \underbrace{\left[\begin{array}{c}
1-y_{i t-1} \\
y_{i t-1}
\end{array}\right]}_{z_{i t-1}},
$$

where the vector of expected outcomes in the current period $E\left(z_{i t} \mid z_{i t-1}, y_{i 0}, x_{i}, a_{i}\right)$ contains the conditional probabilities of benefit non-receipt $E\left(1-y_{i t} \mid y_{i t-1}, y_{i 0}, x_{i}, a_{i}\right)$ and benefit receipt $E\left(y_{i t} \mid y_{i t-1}, y_{i 0}, x_{i}, a_{i}\right)$. At any time $t$, only one of the two potential outcomes in each of these two vectors is realized for a given individual $i$. Similarly, iterating Equation (10), we can write the vector of expected outcomes $s$ periods ahead as

$$
E\left(z_{i t} \mid z_{i t-s}, y_{i 0}, x_{i}, a_{i}\right)=\left(\prod_{j=0}^{s-1} \mathcal{A}_{i t-j}^{\prime}\right) z_{i t-s} .
$$

These derivations illustrate how we are able to simply derive annual transition probabilities from their monthly counterparts if benefit receipt dynamics from period $t$ to $t+1$ follow a Markov process.

As noted, the dynamic random-effects probit model is only assumed to satisfy the Markov property conditional on the covariates and the individual-specific effect. The transition probabilities that we would predict directly based alone on the coefficient estimates and the values of the covariates however are population-averaged, because we have integrated out the individualspecific effect for the construction of the likelihood function. To be able to assess the validity of the Markov assumption and aggregate up estimated transition matrices over time we thus need to reconstruct individual-specific transition matrices from our unconditional predictions.

Denoting the 'unconditional' transition probability matrix as $A_{i t} \equiv A_{i t}\left(y_{i t-1}, y_{i 0}, x_{i}\right)$ and the conditional transition probability matrix as $\mathcal{A}_{i t} \equiv \mathcal{A}_{i t}\left(y_{i t-1}, y_{i 0}, x_{i}, a_{i}\right)$, we can relate transition probabilities at the monthly level by integrating over the random effect as

$$
A_{i t}^{m}=\int \mathcal{A}_{i t}^{m} \frac{1}{\sigma_{a}} \phi\left(\frac{a}{\sigma_{a}}\right) d a,
$$

where we use the superscript $m$ to denote the monthly transition matrix. Similarly, we can write 
the unconditional transition probabilities at the annual level using the superscript $y$ as

$$
A_{i t}^{y}=\int\left(\prod_{s=0}^{11} \mathcal{A}_{i t-s}^{m}\right) \frac{1}{\sigma_{a}} \phi\left(\frac{a}{\sigma_{a}}\right) d a .
$$

Under the assumption of a Markov process at the monthly level, there is thus a one-to-one mapping of monthly into annual transition probabilities.

From a computational point of view, it is easier to generate predictions of the conditional probabilities by sampling from the estimated distribution of the random effect $\mathcal{N}\left(0, \hat{\sigma}_{a}^{2}\right)$ rather than by integrating over this distribution. To produce precise estimates of individual-specific transition rates, we would in this case need multiple simulations for each individual. Since however we are not interested in precise estimates of individual-specific transition rates but only in the population averages, the large size of our sample imply that a single simulation per individual is sufficient.

To assess the degree of state dependence in our model, we can construct predicted conditional transition probabilities $\widehat{\mathcal{A}_{i t}^{m}}$ from our estimated unconditional probabilities $\widehat{A_{i t}^{m}}$ using random draws of $a_{i}$. Specifically, we can predict the entry probability into benefits for an individual in a given period as

$$
\widehat{P}\left(y_{i t}=1 \mid y_{i t-1}=0, x_{i}, y_{i 0}, \tilde{a}_{i}\right)=\Phi\left(x_{i t-1}^{\prime} \hat{\beta}+\hat{\gamma}_{1} y_{i 0}+\bar{x}_{i}^{\prime} \hat{\gamma}_{2}+\tilde{a}_{i}\right),
$$

and the corresponding persistence probability for the same individual as

$$
\widehat{P}\left(y_{i t}=1 \mid y_{i t-1}=1, x_{i}, y_{i 0}, \tilde{a}_{i}\right)=\Phi\left(\hat{\lambda}+x_{i t-1}^{\prime} \hat{\beta}+\hat{\gamma}_{1} y_{i 0}+\bar{x}_{i}^{\prime} \hat{\gamma}_{2}+\tilde{a}_{i}\right) .
$$

where $\tilde{a}_{i}$ is a random draw from the estimated distribution of the random effect. One of these two predicted transition probabilities will always describe the counterfactual.

The difference between the average predicted transition probabilities over all individuals and time periods gives us the estimated average treatment effect (ATE) ${ }^{17}$ as

$$
A T E=\frac{1}{N T} \sum_{i=1}^{N} \sum_{t=1}^{T}\left[\widehat{P}\left(y_{i t}=1 \mid y_{i t-1}=1, x_{i}, y_{i 0}, \tilde{a}_{i}\right)-\widehat{P}\left(y_{i t}=1 \mid y_{i t-1}=0, x_{i}, y_{i 0}, \tilde{a}_{i}\right)\right] .
$$

This ATE describes the estimated average effect of benefit receipt last month on the probability of welfare benefit receipt in the current month.

The two monthly transition probabilities for each individual and period given by Equations (14) and (15) can also be aggregated up to the annual level as described. During this aggregation process, we keep all observable characteristics fixed at their values in period $t-12$, which corresponds to the period in which they are measured in the annual model. Taking the difference between the two aggregated counterfactual probabilities averaged over individuals and years we consequently obtain the annual average treatment effect implied by the estimates from the monthly model. This effect can be readily compared to the average treatment effect derived

\footnotetext{
${ }^{17}$ The term typically used in studies of benefit dynamics is that of the average partial effect (APE), see for instance Wooldridge (2005) and Stewart (2007). We follow Wooldridge (2001, p. 68) in using the term ATE for a discrete variable.
} 
from the transition matrix constructed directly from the estimates of the annual model.

As for the monthly-to-annual aggregation, we can also aggregate the annual transition probabilities to the biennial level using an expression analogue to that in Equation (13) and compare these to the transition probabilities estimated directly from a biennial model. This allows us to test the assumption commonly made in the literature that welfare benefit receipt dynamics follow the conditional Markov property at the annual level. Note that the validity of this time aggregation exercise does not depend on whether we use the 'point-in-time' approach or the 'benefit year' approach to define the annual benefit receipt variable.

In practice, a simpler alternative to this analytical time aggregation of transition probabilities is to directly simulate each individual's benefit receipt path over the twelve-month period. Specifically, we predict an individual's benefit receipt status one period ahead as

$$
\hat{y}_{i t+1}=\mathbb{1}\left\{\hat{\lambda} y_{i t}+x_{i t}^{\prime} \hat{\beta}+\hat{\gamma}_{1} y_{i 0}+\bar{x}_{i}^{\prime} \hat{\gamma}_{2}+\tilde{a}_{i}+\tilde{e}_{i t+1}>0\right\} .
$$

where now both $\tilde{a}_{i}$ and $\tilde{e}_{i t+1}$ are random draws from the respective estimated error distributions. We then use the value for $\hat{y}_{i t+1}$ to again predict the outcome in period $t+\mathscr{2}$ and so forth. By iterating this process twelve times, we can construct an individual's predicted benefit receipt path over an entire year. The result of this aggregation exercise will be the predicted value of the binary outcome variable $\hat{y}_{i 12}$ rather than a predicted transition rate from period $t$ to $t+12$. To calculate the degree of annual state dependence implied by the monthly model, we simply compare the simulated rate of benefit receipt across individuals twelve periods ahead obtained by setting the current benefit receipt variable $y_{i t}$ equal to zero and equal to one, respectively, for all individuals and years. Again, we fix the covariates during this process at their values at time $t$.

The advantage of making period-by-period predictions of a benefit receipt path over aggregating transition matrices is that the approach just described extends easily to the more complex models with duration and occurrence dependence discussed in Section 5.

\subsubsection{Comparing transition probabilities at different levels of time aggregation}

We have illustrated that if monthly benefit dynamics follow a Markov process, there exists a model describing the annualized data that also satisfies the conditional Markov property, with the transition probabilities from that model being known functions of the monthly transition probabilities. Our conjecture is now that for a monthly process that can be adequately described by a dynamic random-effects probit model at the monthly level, the process observed in the annualized data can also be approximated by a random-effects probit structure at the annual level. We hence test the monthly model by comparing predictions obtained from the same dynamic random-effects probit model estimated on monthly and annualized data, aggregating the predictions from the monthly to the annual level as explained above.

This approach comes with a subtle qualification: Unlike for a linear autoregressive model, for which the time aggregation is exact, a dynamic random-effects probit model at the monthly level does not aggregate exactly to a dynamic random-effects probit model at the annual level. While the aggregated annual conditional transition probabilities will be functions of the same covariates and random effects that enter the baseline monthly model, they cannot necessarily 
be approximated by the same probit functional form.

Fortunately, there is an easy way of testing the validity of our approach. If the probit approximation is appropriate, an annual dynamic random-effects probit model should give results identical to those aggregated from a monthly dynamic probit model if the annual model is estimated on data that have been generated by this monthly model. As a robustness check for our time aggregation exercise, we therefore (i) simulate data based on each monthly model we estimate, (ii) estimate the corresponding annual model on an annualized version of these simulated data, and (iii) compare the predictions from the annual model estimated on simulated data with the aggregated predictions from the monthly model that was used to construct the simulated data. Any substantial difference between the two predictions will indicate that the dynamic probit structure does not carry over to higher levels of time aggregation. The simulation exercise thus provides a safeguard against falsely rejecting the conditional Markov property only because the probit structure we assume is a bad approximation at higher levels of time aggregation.

\section{An empirical test of the Markov model for welfare transitions}

To test the assumption that the dynamics of welfare entry and persistence can be jointly described by a dynamic random-effects probit model, we estimate the model on monthly, annual and biennial data and calculate the degree of estimated state dependence at each level of aggregation. We then use the model estimates to simulate benefit transitions from the monthly to the annual level and from the annual to the biennial level. The comparison of estimated and aggregated transition matrices at the annual and biennial level serves as our test of the Markov property. We also compare results based on the 'point-in-time' approach and the 'benefit year' approach for defining the annual benefit receipt variable and assess the time aggregation properties of these two approaches.

In all our models, we control for the usual set of individual characteristics (sex, age, years of education, and immigrant status), household characteristics (family type, household size, and having a child aged 0-5 years), and partner's characteristics (age, years of education, and immigrant status) for married or co-habiting individuals. All our specifications moreover include year dummies and a control for the municipal unemployment rate. Since the focus of our paper is on the analysis of state dependence in welfare benefit receipt, we limit ourselves to reporting average predicted transition rates and the corresponding average treatment effect of past benefit receipt for each specification. Coefficient estimates for the various specifications are reported in the Appendix, Section A.2.

\subsection{Time aggregation for the 'point-in-time' benefit variable}

We begin our empirical analysis by looking at the standard dynamic random-effects probit specification with an outcome variable that measures benefit receipt at one point in time. Using the monthly data on benefit receipt described in Section 2, we estimate the DREP model at the monthly level. To construct a corresponding data set of annual 'point-in-time' observations, we discard eleven of the twelve monthly observations for an individual in each year and only 
keep the benefit receipt status in December. ${ }^{18}$ We then compare the effect of benefit receipt in December of year $t$ on the probability of benefit receipt in year $t+1$ implied by the monthly and the annual specification.

Table 1: Time aggregation: Monthly to Annual ('point-in-time')

\begin{tabular}{lcccc}
\hline \hline & $(1)$ & $(2)$ & $(3)$ & $(4)$ \\
\cline { 2 - 5 } & $\begin{array}{c}\text { Monthly } \\
\text { model }\end{array}$ & $\begin{array}{c}\text { Annual } \\
\text { model }\end{array}$ & $\begin{array}{c}\text { Monthly-to-annual } \\
\text { time aggregation }\end{array}$ & $\begin{array}{c}\text { Simulation-based } \\
\text { specification check }\end{array}$ \\
\hline Avg. predicted persistence rate (in \%) & $14.0(0.2)$ & $7.0(0.2)$ & $3.1(0.1)$ & $2.9(0.0)$ \\
- Avg. predicted entry rate (in \%) & $1.4(0.0)$ & $2.1(0.1)$ & $3.1(0.1)$ & $2.9(0.0)$ \\
$=$ Average treatment effect (in ppts) & $12.6(0.1)$ & $4.9(0.2)$ & $0.0(0.0)$ & $0.0(0.0)$ \\
\hline \hline
\end{tabular}

Note: The monthly model in column (1) and annual model in column (2) refer to the dynamic random-effects probit specifications estimated on monthly and annualized data, respectively. The annualized data for model (2) were obtained by keeping the observations for December of each year only. The monthly-to-annual time aggregation results presented in column (3) were obtained by aggregating the transitions of the monthly model to the annual level using the simulation-based approach described in Section 3.2. Column (4) gives the results from a dynamic random-effects probit model estimated on annualized data simulated from a monthly dynamic randomeffects probit model. Standard errors in parentheses of columns (1) to (3) were calculated using 10 bootstrap replications; predicted transition rates and standard errors in parentheses of columns (4) were calculated based on running the annual model on 10 simulated data sets. Coefficient estimates for the two specifications presented in columns (1) and (2) are reported in Table A.1 in the Appendix.

Table 1 provides evidence on the time aggregation properties of the monthly model. In columns (1) and (2), we report the average predicted transition rates and the resulting average treatment effect of the lagged dependent variable obtained directly from estimating our model using monthly and annualized data, respectively. In column (3), we then give the benefit transition rates and ATE implied by our monthly model when aggregated to the annual level. The results in column (4) finally were obtained by estimating the annual model on data simulated from the monthly model as a robustness check of our functional-form assumption in the annual model.

The results presented in columns (1) and (2) suggest that benefit dynamics are characterized by a considerable degree of state dependence both at the monthly and at the annual level. From our monthly model, we estimate that on average, sample members have a $14.0 \%$ probability of receiving welfare benefits this period if they already received benefits last month. This compares to a probability of entering benefits from last month to the current month of only $1.4 \%$. The resulting average treatment effect, i.e. the effect of benefit receipt last month on the probability of benefit receipt this month, is 12.6 percentage points. Estimates from the annual model imply

\footnotetext{
${ }^{18}$ The advantage of using December as the month for our annual observation is that we observe individuals for an entire year after they enter the sample in January. The approach thus resembles the one used for the 'benefit year' definition, where benefit receipt is recorded over the entire year but household composition and observable characteristics are measured in December. For reasons that will become clearer later, our approach is advantageous moreover for the models of duration and occurrence dependence that we present in Section 5. Immervoll, Jenkins \& Königs (2014) show that there is some seasonality in benefit receipt for individuals in their low 20s, who are more likely to access welfare benefits during the summer months to bridge gaps in their educational schedules. When including calendar-month dummies in our standard specification, we however find that in spite of the large sample size, only two of the eleven dummies are estimated to have a coefficients statistically different from zero. The ATEs of these two calendar month dummies on benefit receipt are just above 0.1 percentage points. We therefore conclude that the choice of December as the month for annual observations is unlikely to affect our results.
} 
a somewhat lower average treatment effect at the annual level. Conditional on benefit receipt in December of last year, the probability of benefit receipt in December of this year is $7.0 \%$, compared to a $2.1 \%$ probability of receiving benefits today conditional on non-receipt twelve months ago. The resulting average treatment effect is 4.9 percentage points.

Of largest interest are the results presented in column (3), which gives the annual transition probabilities implied by the predicted monthly transition probabilities. Based on the estimates of the monthly model, the probability of benefit receipt in the current period is virtually independent of whether an individual did or did not receive welfare benefits twelve months ago. The simulation-based results give an annual average treatment effect of zero that is moreover very precisely estimated. Intuitively, the relatively low average predicted month-to-month persistence probability of $14 \%$ implies that very few individuals remain on welfare for the entire year. The predicted probability of benefit receipt thus quickly converges to the equilibrium rate of $3.1 \%$ even for those individuals who received benefits twelve months ago.

As discussed, transition probabilities aggregated up from the monthly to the annual level should be comparable to those estimated from an annual model directly if the conditional Markov property is satisfied. Our dynamic random-effects probit model estimated at the monthly level predicts that benefit receipt twelve months ago does not have an impact on the probability of benefit receipt today once we control for observed and unobserved heterogeneity. This finding of no year-to-year state dependence in benefits based on the monthly model clearly differs from the one obtained from our annual model directly, where we estimated an average treatment effect of 4.9 percentage points. This leads us to conclude that the Markov assumption is not satisfied at the monthly level.

As pointed out in Section 3.2, this time aggregation exercise is valid only if the benefit receipt process observed in the annualized data can be approximated by a similar type of dynamic random-effects probit model as the probit model we estimated at the monthly level. To check the validity of this assumption, we report results from a simulation exercise in column (4) of Table 1. We constructed ten data sets based on the estimates from the monthly model, each of which we used to extract annual data, estimate an annual dynamic random-effects probit model on these data, and calculate predicted transition rates and average treatment effects. Column (4) presents the mean and standard deviation of these transition rates and average treatment effects over the ten replications.

We find that the results obtained from estimating the annual model based on simulated data are nearly identical to those derived from aggregating monthly predicted transition rates to the annual level as presented in column (3). This suggests that it is indeed reasonable to assume that our dynamic random-effects probit assumption carries through as transition rates are aggregated from the monthly to the annual level. The large difference in results between the two annual models when estimated on the true data (column (2)) and the simulated data (column (4)) moreover highlight again that the true data-generating process is very different from the monthly dynamic random-effects probit model that we have used for simulation.

The same exercise shows that the time aggregation properties implied by the Markov assumption also fail to hold at the annual level. This time, we aggregate up results from an annual model to the biennial level and compare the level of state dependence with that obtained from 
a specification estimated on biennial data directly. These biennial data were constructed by keeping the observation for December of every second year only while dropping all remaining 23 months.

Table 2: Time aggregation: Annual to Biennial ('point-in-time')

\begin{tabular}{lccc}
\hline \hline & $(1)$ & $(2)$ & $(3)$ \\
\cline { 2 - 4 } & $\begin{array}{c}\text { Annual } \\
\text { model }\end{array}$ & $\begin{array}{c}\text { Biennial } \\
\text { model }\end{array}$ & $\begin{array}{c}\text { Annual-to-biennial } \\
\text { time aggregation }\end{array}$ \\
\hline Avg. predicted persistence rate (in \%) & $7.3(0.3)$ & $5.7(0.3)$ & $3.9(0.1)$ \\
- Avg. predicted entry rate (in \%) & $2.0(0.1)$ & $2.2(0.1)$ & $2.5(0.1)$ \\
= Average treatment effect (in ppts) & $5.2(0.3)$ & $3.5(0.3)$ & $1.5(0.1)$ \\
\hline \hline
\end{tabular}

Note: The annual model in column (1) and biennial model in column (2) refer to the dynamic random-effects probit specifications estimated on annualized and biennialized data, respectively. The annualized data for model (1) were obtained by keeping the observations for December of each year only, while in the biennialized data for model (2) we keep observations for December of every second year only. The annual-to-biennial time aggregation results presented in column (3) were obtained by aggregating the transitions of the annual model to the biennial level using the simulation-based approach described in Section 3.2. Standard errors in parentheses were calculated using 10 bootstrap replications. Coefficient estimates of the two specifications presented in columns (1) and (2) are reported in Table A.2 in the Appendix.

In analogy to above, we report in columns (1) and (2) of Table 2 the estimates obtained directly from the annual and biennial models, while column (3) gives the average predicted transition probabilities and ATEs obtained from aggregating annual benefit transitions to the biennial level. As before, we find significant state dependence both in the annual and biennial model of welfare dynamics with ATEs of 5.2 and 3.5 percentage points, respectively. Aggregated to the biennial level, the transition probabilities from the annual model however imply an average treatment effect of 1.5 percentage points. The state dependence over two years implied by a Markov model at the annual level is thus substantially lower than the ATE we obtain from estimating the model directly with biennial data. For a point-in-time measure of benefit receipt, the assumption that benefit dynamics follow a Markov process must thus be rejected also at the annual level.

\subsection{Time aggregation for the 'benefit year' variable}

As discussed in Section 3.2, the second widely-used approach for defining an annual welfare benefit receipt variable has been to look at receipt at any time during the calendar year. Arguably, the time aggregation problem for such a variable is even more severe because this approach makes no assumption on the timing of benefit receipt during the year. For instance, we might think of a case in which a single spell of benefit receipt extends from December of one year to January of the next, and a second case with two separate spells in January and December of two subsequent years separated by 22 months without benefit receipt. These two cases are observationally equivalent under the 'benefit year' approach, whereas we would expect them to have very different implications for the degree of annual state dependence. ${ }^{19}$

\footnotetext{
${ }^{19}$ For a discussion of the 'benefit year' approach and the advantages of point-in-time sampling see Ellwood (1982).
} 
Using an approach similar to the one employed in the previous subsection, we assess the validity of the Markov assumption for a model of benefit dynamics in which annual benefit variable is defined using the 'benefit year' approach. We construct an annual data set of benefit receipt coding an individual as a benefit recipient if any benefit payments were recorded during the calendar year. In the corresponding data set of biennial observations, we only keep the observations for odd calendar years. All observable characteristics are recorded in December of the respective year. The results of this analysis are presented in Table 3.

Table 3: Time aggregation: Annual to Biennial ('benefit year')

\begin{tabular}{lccc}
\hline \hline & $(1)$ & $(2)$ & $(3)$ \\
\cline { 2 - 4 } & $\begin{array}{c}\text { Annual } \\
\text { model }\end{array}$ & $\begin{array}{c}\text { Biennial } \\
\text { model }\end{array}$ & $\begin{array}{c}\text { Annual-to-biennial } \\
\text { time aggregation }\end{array}$ \\
\hline Average persistence rate (in \%) & $20.1(0.4)$ & $12.0(0.5)$ & $10.6(0.2)$ \\
- Average entry rate (in \%) & $4.4(0.1)$ & $5.1(0.1)$ & $6.2(0.1)$ \\
$=$ Average treatment effect (in ppts) & $15.7(0.4)$ & $6.8(0.6)$ & $4.5(0.2)$ \\
\hline \hline
\end{tabular}

Note: The annual model (1) and biennial model (2) refer to the dynamic random-effects probit specifications estimated on annualized and biennialized data, respectively. The annualized data for model (1) measure benefit receipt at any time during the calendar year, while in the biennialized data for model (2) we measure benefit receipt at any time during every second calender year. The annual-to-biennial time aggregation results presented in column (3) were obtained by aggregating the transitions of the annual model to the biennial level using the simulation-based approach described in Section 3.2. Standard errors in parentheses were calculated using 10 bootstrap replications. Coefficient estimates of the two specifications presented in columns (1) and (2) are reported in Table A.3 in the Appendix.

Benefit receipt rates and the level of state dependence are substantially higher for the 'benefit year' approach than for the 'point-in-time' approach presented in Table 2. We calculate a predicted persistence rate into benefit receipt of $20.1 \%$ and an entry rate of $4.4 \%$, which translates into an ATE of benefit receipt in the past year on benefit receipt this year of 15.7 percentage points. This effect is more than three times as large as the one for the point-in-time measure of benefit receipt reported in column (1) of Table 2.

Again, we find that the model fails our time aggregation test: When estimating our model on biennial data, we obtain an ATE of 6.8 percentage points; once we aggregate the results from the annual model to the biennial level, the ATE drops to only 4.5 percentage points.

The Markov assumption thus seems to be violated at the annual level also when we define the benefit variable using the 'benefit year' approach. The two approaches to defining the benefit variable moreover yield very different estimates of predicted transition rates and state dependence at the annual level.

\subsection{A model with higher-order lags}

Our findings thus far show that standard models of welfare benefit dynamics do not aggregate over time as one should expect if the Markov assumption were true either at the monthly or at the annual level. An alternative, more illustrative test of the Markov specification at the monthly level is to add higher-order lags to the standard specification and check for their significance.

Consistent estimation of such a higher-order dynamic probit model however is a little more 
complicated than it may appear at first, because like the first lag, also the higher-order lags will be endogenous due to their positive correlation with the unobserved individual-specific random effect $\alpha_{i}$. Unless this endogeneity problem is appropriately addressed, one should expect to obtain non-zero coefficients for the higher-order terms even if these terms do not indeed matter for determining benefit transition rates.

To allow for higher-order state dependence, we modify the standard model presented in Equation (1) as

$$
y_{i t}=\mathbb{1}\left\{\sum_{s=1}^{12} \lambda_{s} y_{i t-s}+x_{i t-1}^{\prime} \beta+\alpha_{i}+\varepsilon_{i t}>0\right\} \quad \text { for } i=1, \ldots, N ; t=12, \ldots, T_{i},
$$

where we have included twelve lags of the dependent variable with the coefficients $\lambda_{1}$ to $\lambda_{12}$. We extend our controls for the initial conditions by now including the values of the outcome variable in the initial twelve periods of the panel in addition to the individual longitudinal averages of the covariates $\bar{x}_{i}$, writing

$$
\alpha_{i}=\gamma_{0}+\sum_{s=0}^{11} \gamma_{1, s} y_{i s}+\bar{x}_{i}^{\prime} \gamma_{2}+a_{i}
$$

Under distributional assumptions similar to those discussed in Section 3.1, we can then integrate out $\alpha_{i}$ and estimate this model using conditional maximum likelihood methods (see Appendix, Section A.1). ${ }^{20}$

Figure 2 plots the estimated average treatment effects of the first twelve lags and their $95 \%$ confidence intervals. We find that all of these ATEs are significantly different from zero, which means that we can reject the Markov model also on purely statistical grounds. Economicallyspeaking however, only the second and possibly the third lag are of a meaningful magnitude with estimated ATEs of 1.8 and 0.6 percentage points, respectively. Even for those two lags, the estimated effect is already much smaller than the ATE of 8.1 percentage points for the first lag.

The low importance that our model attributes to the higher-order lags implies that it provides little guidance as to why the first-order Markov specification fails as dramatically in terms of its time aggregation properties as observed in Table 1. Indeed, based on the results of the higherorder specification alone, we might have concluded that a first-order Markov model is a relatively good approximation to the underlying benefit dynamics. This underlines the importance of the time-aggregation test we performed in this section and which demonstrated that first-order Markov models do not provide robust estimates of the level of state dependence in benefit receipt.

A drawback of the higher-order Markov specification in our view is moreover that it is difficult to give higher-order lags a meaningful economic interpretation. In the following section, we therefore generalize and extend the models just presented by allowing for different processes

\footnotetext{
${ }^{20}$ Stewart (2007, Section 4.4) estimates a second-order dynamic random-effects probit model in his study of unemployment and low pay. He uses an extension of the Wooldridge approach similar to ours although for a more complex state space and additionally includes interactions of the two initial lags of the outcome variable with the longitudinal averages of the covariates. Andrén \& Andrén (2013) estimate a similar model, also including third-order lags, in their study of social assistance dynamics in Sweden. Both of these studies are based on annual data.
} 


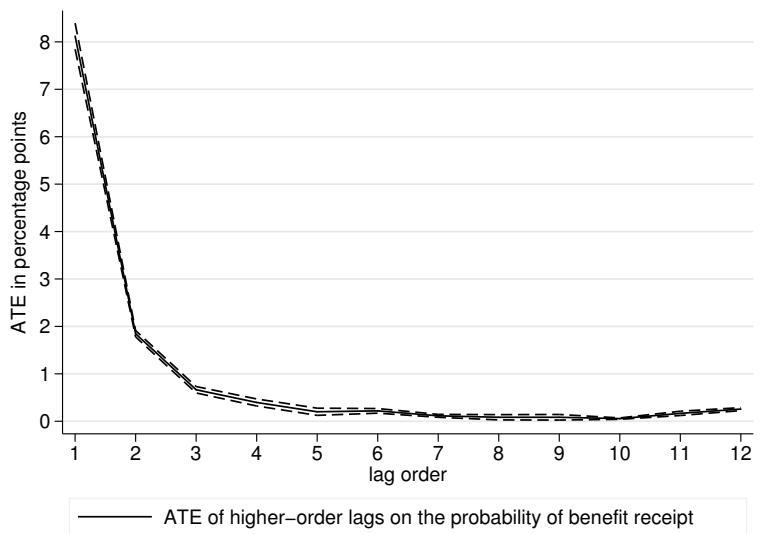

Note: Average treatment effects of higher-order lags in a dynamic random-effects probit model estimated on monthly data. The dashed lines give the $95 \%$ confidence interval obtained from 10 bootstrap replications.

Figure 2: Average treatment effects in the higher-order Markov model

to determine entries into and persistence in benefit receipt and by accounting explicitly for duration and occurrence dependence in each of these processes.

\section{A general dynamic model of welfare entry and persistence}

A restriction of the models discussed thus far is that they treat entries into benefit receipt and persistence in benefit receipt symmetrically in a single, joint specification. In the standard Markov model, the effect of lagged benefit receipt $y_{i t-1}$ on the probability of benefit receipt in the current period $y_{i t}$ is fully captured by the state dependence parameter $\lambda$. All other parameters of the model, notably the vector of coefficients $\beta$ and the individual-specific effect $\alpha_{i}$, are assumed not to depend on lagged benefit receipt status. The model thus constrains observed and unobserved characteristics to have the same effect on the probability of entries into and persistence in benefit receipt.

A second limitation is the way we have modelled the relationship between past and present benefit receipt. The standard conditional Markov model assumes that only the benefit receipt status in the last period affects the likelihood of benefit receipt today conditional on $y_{i t-1}, x_{i t-1}^{\prime}$ and $\alpha_{i}$. When relaxing this assumption in Section 4.3 by including higher-order lags, we however found at least some evidence that the fit of the monthly DREP model could be improved by accounting for an individual's earlier benefit receipt history.

In this section, we extend the standard Markov model in two steps to permit more complex benefit dynamics. First, we introduce a more flexible random-coefficient specification that allows capturing differential effects of observed individual characteristics and unobserved individualspecific heterogeneity on entries and persistence. Second, we allow for duration and occurrence dependence in benefit receipt, two channels through which the earlier benefit history can impact the probability of benefit receipt and that might explain the observed pattern of significant higher-order lags. For brevity, we refer to this extended specification as a dynamic randomcoefficients probit (DRCP) model with duration and occurrence dependence. As for the standard model, we estimate the DRCP specification at the monthly level before we move on to examine the time-aggregation properties of this model. 


\subsection{The DRCP model with duration and occurrence dependence}

To extend the standard dynamic random-effects probit model, we first abandon the assumption of a symmetric process for both entries and persistence probabilities. Using the notation from Equation (1), we write

$$
\begin{aligned}
y_{i t}= & \mathbb{1}\left\{\left(\bar{\lambda}+\lambda_{i}\right) y_{i t-1}+x_{i t-1}^{\prime}\left(\beta+y_{i t-1} \eta\right)+\alpha_{i}+\varepsilon_{i t}>0\right\} \\
& \text { for } i=1, \ldots, N ; t=12, \ldots, T_{i} .
\end{aligned}
$$

There are two important differences between this model and the standard specification described in Equation (1). First, we have added a vector of interaction terms between the lagged dependent variable $y_{i t-1}$ and the covariates $x_{i t-1}$ with an associated coefficient vector $\eta$. These interactions allow the effects of covariates like age, sex, or family status to differ for the processes that determine entry into benefit receipt (as measured by $\beta$ ) and persistence in benefit receipt (measured by $\beta+\eta$ ). Second, we include a random coefficient $\lambda_{i}$ for the lagged dependent variable that can be correlated with the random effect $\alpha_{i}$. This random coefficient captures the individual-specific effect of past benefit receipt $y_{i t-1}$ on the probability of current benefit receipt $y_{i t}$ in terms of the deviation from the average effect measured by $\bar{\lambda}$. An equivalent but for our purposes more convenient interpretation of $\lambda_{i}$ is as a second random effect that is interacted with the lagged dependent variable and therefore allows persistent unobserved heterogeneity to differ for the entry and persistence processes. ${ }^{21}$ Note that this random-coefficients framework generalizes the standard Markov model, as the DRCP model in Equation (20) collapses to the DREP model in Equation (1) for $\eta=0$ and $\lambda_{i}=0 \forall i{ }^{22}$

Assuming $\varepsilon_{i t} \sim \mathcal{N}(0,1)$ as before, we can express the probability of entry into benefit receipt as

$$
P\left(y_{i t}=1 \mid y_{i t-1}=0, x_{i}, \alpha_{i}, \lambda_{i}\right)=\Phi\left(x_{i t-1}^{\prime} \beta^{0}+\alpha_{i}^{0}\right),
$$

where $\beta^{0}=\beta$ and $\alpha_{i}^{0}=\alpha_{i}$. Similarly, the probability of persistence in benefit receipt is given as

$$
P\left(y_{i t}=1 \mid y_{i t-1}=1, x_{i}, \alpha_{i}, \lambda_{i}\right)=\Phi\left(\bar{\lambda}+x_{i t-1}^{\prime} \beta^{1}+\alpha_{i}^{1}\right),
$$

where $\beta^{1}=(\beta+\eta)$ and $\alpha_{i}^{1}=\left(\alpha_{i}+\lambda_{i}\right)$. Entry and persistence probabilities in our DRCP model can thus be thought of as coming from two separate equations with different coefficient vectors $\beta^{0}$ and $\beta^{1}$ and two distinct random effects $\alpha_{i}^{0}$ and $\alpha_{i}^{1}$, which however are allowed to be correlated.

We further extend this model by abandoning the first-order Markov assumption in the above

\footnotetext{
${ }^{21}$ Stewart (2007, Section 3.7) also introduces heterogeneity in state dependence in a model of unemployment and low pay dynamics by specifying a random coefficient for the lagged dependent variable without however allowing the effects of the covariates to vary by lagged benefit receipt status. Meanwhile, Cappellari \& Jenkins (2009) introduce interaction terms between the explanatory variables and the lagged dependent variable in a model of welfare benefit receipt yet restrict unobserved heterogeneity to have the same effect on entries and persistence. Our specification thus combines these two approaches, moreover using monthly rather than annual data.

${ }^{22}$ We estimate the described model over the periods $t=12, \ldots, T$ only. This is not a feature of the DRCP model, but a restriction we impose in order to be able to account for endogeneity of the additional duration and occurrence dependence variables to be added below based on an extension of the Wooldridge approach. For the remaining analysis, we therefore write $y_{i 11}$ rather than $y_{i 0}$ when referring to the outcome in the initial period.
} 
specification and allow for more sophisticated ways in which past benefit receipt can impact the likelihood of benefit receipt in the current period. Specifically, we implement some of the theoretical concepts introduced by Heckman \& Borjas (1980) to extend our DRCP model to account for duration and occurrence dependence in welfare benefit receipt.

A standard assumptions made in event-history models of benefit persistence is that a recipient's probability of leaving benefits depends on the length of the ongoing spell. In the case of unemployment, persistent joblessness might lead to a deterioration of labour market skills and networks over time thereby reducing an individual's probability of finding new employment. In the case of welfare benefits, a recipient might grow disillusioned or frustrated with increased duration of benefit receipt and reduce efforts to become self-sufficient. Similarly, there might be duration dependence outside of benefit receipt if job security or the level of pay rise over time makes an individual less likely to enter welfare as the time spent off benefits rises. Each of these are theoretical justifications for negative duration dependence in the probability of exits from welfare benefit receipt and self-sufficiency, respectively. Also, the number of previous benefit spells an individual has had might matter for the risk of future benefit receipt. Intuitively, individuals without a previous welfare history might worry about a potential stigma from benefit receipt that makes them more reluctant to claim benefits. Persons who previously received benefits might be less susceptible to this type of stigma. There might also be information or time costs to claiming benefits that decline if the individual has submitted a claim before. In such cases, the probability of benefit receipt is positively related to the incidence (or the number) of previous benefit spell(s), which Heckman \& Borjas (1980) refer to as occurrence dependence.

To incorporate duration and occurrence dependence into our DRCP model, we allow the probability of benefit receipt to depend on a series of dummy variables that describe the duration of the ongoing spell on or off welfare and the number of previous spells since the start of an individual's welfare career. ${ }^{23}$ Further extending Equations (21) and (22), we write the probability of entry into welfare as

$$
P\left(y_{i t}=1 \mid y_{i t-1}=0, x_{i}, d_{i}^{0}, d_{i}^{1}, o_{i}, \alpha_{i}, \lambda_{i}\right)=\Phi\left(x_{i t-1}^{\prime} \beta^{0}+\sum_{k=2}^{12} \phi_{k}^{0} d_{i k t-1}^{0}+\sum_{k=1}^{11} \psi_{k}^{0} o_{i k t-1}+\alpha_{i}^{0}\right),
$$

and the probability of persistence in welfare as

$$
P\left(y_{i t}=1 \mid y_{i t-1}=1, x_{i}, d_{i}^{0}, d_{i}^{1}, o_{i}, \alpha_{i}, \lambda_{i}\right)=\Phi\left(\bar{\lambda}+x_{i t-1}^{\prime} \beta^{1}+\sum_{k=2}^{12} \phi_{k}^{1} d_{i k t-1}^{1}+\sum_{k=1}^{11} \psi_{k}^{1} o_{i k t-1}+\alpha_{i}^{1}\right) .
$$

The $2 \times 11$ dummy variables $d_{i k t-1}^{0}$ and $d_{i k t-1}^{1}$ indicate whether, in period $t-1$, the ongoing spell off or on welfare, respectively, had lasted for exactly $k$ periods. The reference case is the first month of a spell on or off welfare. We restrict the effect of ongoing spells with a duration of more than eleven months to be constant adding single dummies $\left(d_{i 12 t-1}^{0}, d_{i 12 t-1}^{1}\right)$ for durations of twelve months and longer. Similarly, the set of dummy variables $o_{i k t-1}$ indicate whether until period $t$ - 1 the individual had terminated exactly $k$ previous benefit spells, the reference

\footnotetext{
${ }^{23}$ Heckman \& Borjas also suggest that there might be lagged duration dependence, i.e. a dependence of the probability of benefit receipt of the duration of past benefit spells. Since modelling lagged duration dependence would have further increased the complexity of our specification, we ignore it in our analysis.
} 
case being no previous benefit spells. Again, we specify separate dummies only for the first ten occurrences of benefit receipt and capture the effects of having eleven or more previous welfare spells through a single dummy $o_{i 11 t-1}$. Note that the processes we model start in period $t=12$, i.e. the month of an individual's $19^{t h}$ birthday. Dummies $\left(d_{i k}^{0}, d_{i k}^{1}, o_{i k}\right)$ can therefore be measured for each individual in our sample from the beginning of the individual's welfare career.

The specification is very flexible in its treatment of duration and occurrence dependence: The effect of spell durations is allowed to differ across the processes of entries and persistence as captured by the two separate sets of dummy variables $d_{i k}^{0}$ and $d_{i k}^{1}$ with coefficients $\phi_{k}^{0}$ and $\phi_{k}^{1}$. The number of previous spells enters through a single set of dummies $o_{i k}$ with separate sets of coefficients $\psi_{k}^{0}$ and $\psi_{k}^{1}$ for the entry and persistence process, respectively. As before, the model allows the effects of observable individual characteristics $x_{i t-1}$ and persistent unobserved heterogeneity $\left(\alpha_{i}^{0}, \alpha_{i}^{1}\right)$ to differ between entries and persistence in benefit receipt. This model is a generalization of the specification in Equation (20) without duration and occurrence dependence and hence of the standard DREP model. ${ }^{24}$

A challenge for estimation of the above specification is that the DRCP model with duration and occurrence dependence is likely to suffer from a much more serious endogeneity problem than the specifications discussed earlier. In particular, the unobserved heterogeneity terms $\alpha_{i}^{0}$ and $\alpha_{i}^{1}$ are no longer correlated only with the lagged dependent variable but now also with each of the duration and occurrence dummies that are functions of past benefit receipt. To be able to integrate out the individual-specific error components for consistent estimation, we therefore need to also extend our set of controls for initial conditions.

To account for the endogeneity of initial conditions, we again follow the approach by Wooldridge (2005), which now translates into expressing the two individual-specific 'random effects' $\alpha_{i}^{0}$ and $\alpha_{i}^{1}$ as linear functions of the receipt status in the initial period $y_{i 11}$ and a vector of individual longitudinal averages of time-varying covariates $\bar{x}_{i}$. Unlike previously, we now however add also both sets of duration dummies (on and off welfare) and the occurrence dummies, all measured in the initial period. We thus do not only control for the benefit receipt status in the initial period but also for how long the individual had been in this state at that point in time and for how many previous spells the individual has had. The resulting expression for the individual-specific effects $\alpha_{i}^{0}$ and $\alpha_{i}^{1}$ can be written as

$$
\alpha_{i}^{j}=\gamma_{0}^{j}+\gamma_{1}^{j} y_{i 11}+\bar{x}_{i}^{\prime} \gamma_{2}^{j}+\sum_{k=2}^{12} \gamma_{3, k}^{j} d_{i k 11}^{0}+\sum_{k=2}^{12} \gamma_{4, k}^{j} d_{i k 11}^{1}+\sum_{k=1}^{5} \gamma_{5, k}^{j} o_{i k 11}+a_{i}^{j},
$$

for $j=0,1 .{ }^{25}$ Note that depending on whether the individual is on or off welfare in the initial period $y_{i 11}$, either of the two sets of duration variables in the initial period $d_{i 11}^{0}$ and $d_{i 11}^{1}$ will be

\footnotetext{
${ }^{24}$ We could again have written this DRCP model with duration and occurrence dependence in form of a single equation analogous to Equation (20), where each coefficient in the persistence process would be written as the sum of the corresponding coefficient for the entry process and the coefficient of an interaction term with the lagged dependent variable. An exception are the coefficients of the duration dummies, as these dummies are by construction coded as being equal to zero if the individual is not in the respective state. For $\phi_{k}^{0}=\psi_{k}^{0}=\phi_{k}^{1}=$ $\psi_{k}^{1}=0 \forall k$, the model in Equations (23)-(24) reduces to the simpler specification in Equations (21)-(22) without duration and occurrence dependence.

${ }^{25}$ The index $k$ of the sum over the occurrence dummies for the initial spell only runs up to five as this is the maximum number of previous spells that can be observed in the data in the twelve months leading up to the initial period.
} 
all zero.

We require the residual unobserved heterogeneity terms $a_{i}^{0}$ and $a_{i}^{1}$ to follow a bivariate normal distribution with zero means, variances $\left(\sigma_{a_{0}}^{2}, \sigma_{a_{1}}^{2}\right)$ and a correlation $\tau$. As in the standard case, they are moreover uncorrelated with the covariates in the model $\left(x_{i t-1}, \bar{x}_{i}, y_{i 11}\right)$ and the transitory shock $\varepsilon_{i t}$. Under these distributional assumptions, we can integrate out $\left(a_{i}^{0}, a_{i}^{1}\right)$ to estimate the model parameters on monthly data using conditional maximum likelihood methods. For a further discussion of this 'extended' Wooldridge approach, see Section A.1 of the Appendix. ${ }^{26}$ In the special case where $a_{i}^{0}$ and $a_{i}^{1}$ are uncorrelated, our approach is equivalent to estimating two separate equations for entries and persistence in benefit receipt.

By allowing for essentially separate processes for entries into and persistence in benefit receipt and by explicitly modelling duration dependence in benefit receipt we transform our DRCP model into a quite general two-state discrete-time event-history model. One main difference from standard applications of event-history models is that as a way to handle the initial conditions problem, data used for such models typically come from flow sampling, that is, a sample from the population of e.g. those who enter welfare receipt in given period. Our modelling framework instead uses data from population sampling including both recipients and non-recipients, and we explicitly account for the endogeneity of initial conditions employing the approach proposed by Wooldridge (2005). ${ }^{27}$ Our random-coefficients modelling framework can thus be viewed as a synthesis of dynamic discrete-choice modelling and event-history modelling, in essence proposing a dynamic discrete-choice model that nests a discrete-time event-history model. It thus facilitates the application of recent solutions to the initial conditions problem developed for dynamic discrete-choice models to event-history analysis. Like certain event-history models, our framework moreover exploits the availability of data on multiple spells in panel data sets as a source of identifying variation that allows us to distinguish duration dependence and unobserved heterogeneity in each state (Honoré, 1993; Van den Berg, 2001).

\subsection{Duration and occurrence dependence in welfare transitions}

There are two main difficulties for an empirical assessment of duration and occurrence dependence in benefit receipt. First, the measurement of precise spell durations and spell numbers requires data on benefit receipt with short observation intervals, which, as discussed, are rarely available for research purposes. Second, even in such data, information on an individual's benefit receipt prior to the start of the observation period will be missing. The number of benefit spells counted for an individual in the data will therefore typically not adequately reflect the individual's entire 'welfare career'. The administrative data that we use allow us to address both of these issues. Since the data set provides high-quality information on benefit receipt at the monthly level, we can construct exact measures of the number and duration of individuals' benefit spells. Even short spells or temporary departures from welfare are reflected in the

\footnotetext{
${ }^{26} \mathrm{An}$ alternative approach to the initial conditions problem would have been to estimate the model over the entire period $t=1, \ldots, T$ rather than $t=12, \ldots, T$, and to assume that we truly observe the start of the process we are modelling on each individual's $18^{\text {th }}$ birthday by setting $y_{i 0}=0 \forall i$. We believe that the approach we use is preferable, because it does not impose exogeneity of the initial conditions.

${ }^{27}$ Bratsberg, Raaum \& Røed (2010) estimate a model for migrants' transitions between employment and nonemployment with duration dependence in each state comparable to our model. They avoid the initial conditions problem by working with a sample of individuals who start with an initial employment spell of three years.
} 

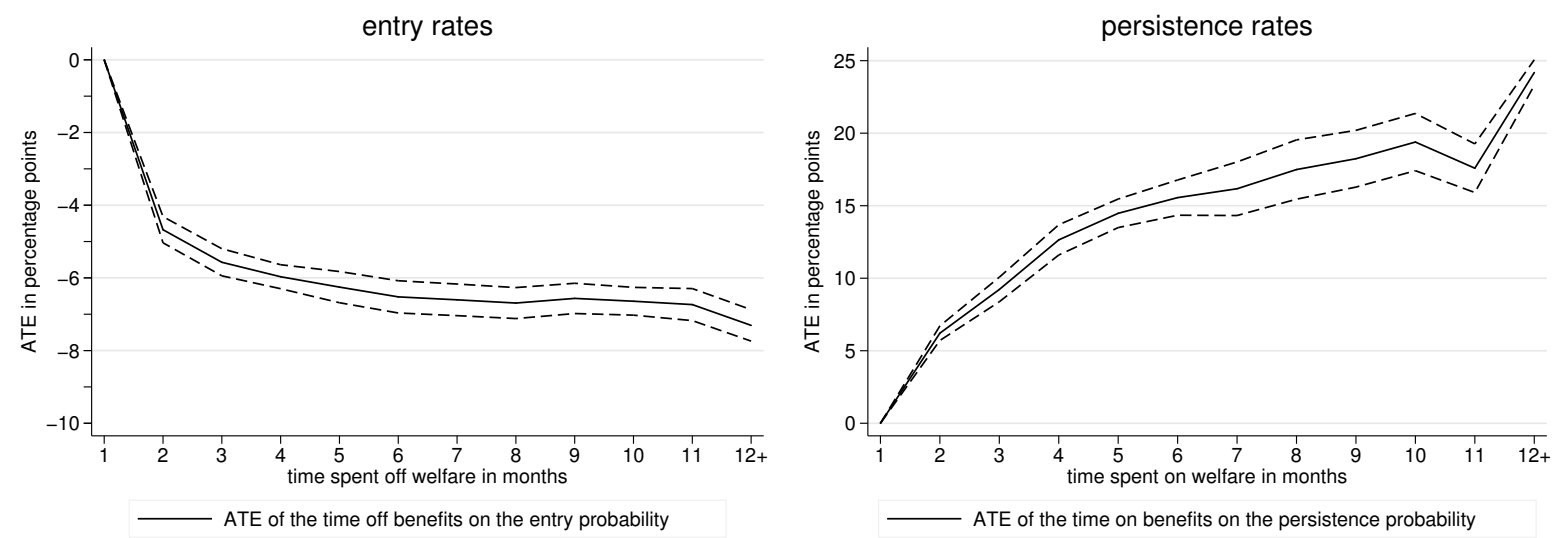

Note: Average treatment effects have been calculated based on the coefficient estimates reported in Table A.5 in the Appendix. An individual's number of previous benefit spells and all covariates are kept fixed in the calculations. ATEs are calculated with spell durations of one month on / off benefits as the reference category. The dashed lines give $95 \%$ confidence intervals obtained by bootstrapping with 10 replications.

Figure 3: Duration dependence in entry and persistence rates

analysis. The large size of the data set moreover allows us to restrict our sample to individuals whom we observe from the moment they become entitled to claim welfare benefits on their $18^{\text {th }}$ birthday. This means that we can indeed count the number of spells each individual has had since the beginning of the welfare career for a sample of sufficient size.

To illustrate the importance of duration and occurrence dependence in welfare benefit receipt dynamics, we start by presenting ATEs of spell durations and occurrences on the probability of benefit receipt. Figure 3 plots the average treatment effect of the time spent on and off welfare on the probability of welfare persistence and welfare entry, respectively. We obtain these ATEs by predicting the probability of benefit receipt in the next month while varying the time on or off benefits for each individual for the respective values of the lagged receipt status. ATEs are expressed in reference to a spell in its initial month either on or off welfare. All other characteristics of the individual, including the occurrence variables, are kept fixed at their observed values. ${ }^{28}$

We find substantial duration dependence both on and off welfare. In the left panel, we give the average treatment effect of the duration off benefits on the rate of welfare entry. We find a strongly declining pattern from the first to the second period of benefit receipt. The probability of entering benefits is about 5 percentage points lower for an individual who has been off benefits for two periods compared to the initial period off benefits. The ATE becomes more negative as the time off benefits rises, however at a strongly declining rate approaching a negative 7 percentage points for spells of length 6 months or longer. An individual who has not received benefits for the last 12 months is thus ceteris paribus about 7-8 percentage points less likely to enter benefits the next month than if he were in his first month off benefits.

The right panel shows very strong duration dependence also for persistence in benefit receipt. Individuals in the second month of their welfare spell are about 5 percentage points more likely to stay on benefits than if they were in their initial month on benefits. The effect further

\footnotetext{
${ }^{28}$ Since occurrence variables are defined as the number of completed welfare spells, neither being on or off welfare is inconsistent with any value for the occurrence variable.
} 

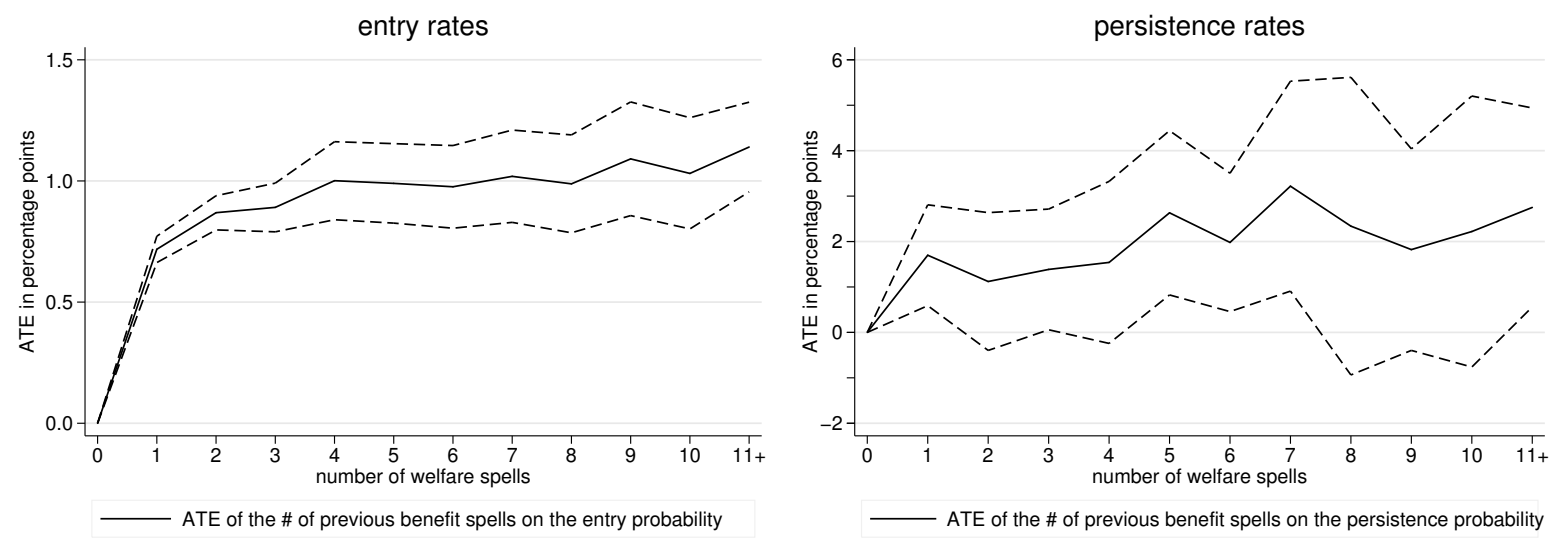

Note: Average treatment effects have been calculated based on the coefficient estimates reported in Table A.5. For the calculation of the ATEs, an individual's benefit receipt status, the duration of the ongoing spell and all covariates are kept fixed in the calculations. ATEs are calculated using the case of no previous benefit receipt as the reference category. The dashed lines give $95 \%$ confidence intervals with standard errors obtained by bootstrapping with 10 replications.

\section{Figure 4: Occurrence dependence in entry and persistence rates}

increases strongly with additional time on benefits reaching 15 percentage points or more for benefit spells of duration 5 months or longer.

We produce similar calculations for the set of occurrence dummies included in our model and present the average treatment effects of previous spell occurrences on welfare entry and persistence rates in Figure 4. Again, these ATEs are obtained by varying only the number of previous benefit spells an individual has had and the lagged benefit receipt status while keeping the individual's current spell duration on or off benefits, respectively, fixed at the observed value.

Results suggest that a history of previous welfare benefit receipt substantially increases the likelihood of entry into benefits, but that the number of previous benefit spells matters little beyond the first spell. As shown in the left panel of Figure 4, we find a significantly positive average treatment effect of having had previous spells in benefit receipt; the size of this effect is relatively stable across spell numbers at around 0.8-1 percentage points.

We do not find a comparable effect of the number of previous benefit spells on the probability of persistence in benefit receipt. While we calculate a mildly positive average treatment effect of previous benefit spells on benefit persistence, five of the eleven occurrence dummies reported in Table A.5 are not significant at the $5 \%$ level. ATEs plotted in the right panel of Figure 4 give a similar result.

Overall, the finding of substantial duration dependence in the processes leading up to entries and persistence in benefit receipt and of occurrence dependence in entry rates into benefit receipt suggests that the extended DRCP model might indeed provide a substantial improvement over our simpler specifications. The pattern of the occurrence dependence we find may be consistent with a theory of stigma or information costs: Experiencing benefit receipt today leads to a permanent rise in the likelihood of re-entry into benefits in the future, but any later spells do not further raise the benefit entry rate. 


\subsection{Time aggregation in a DRCP model for welfare transitions}

To assess the performance of our DRCP model, we again use model estimates to predict welfare entry and persistence rates for each individual and compute the degree of implied state dependence in benefit receipt. We allocate to each individual in the sample a counterfactual benefit receipt status, which now comes with a spell duration and number of potential previous spell. The degree of measured state dependence therefore depends on the assumptions we make about how long each individual has been on or off benefits and on how many previous benefit spells she has had. To get estimates comparable to those for the standard Markov model in Section 4.1, we assume that individuals are as close as possible to a 'clean' benefit receipt history: Average predicted entry rates are constructed under the assumption that an individual had no previous benefit receipt and spent the maximum duration off benefits in the current spell. Similarly, average predicted persistence rates are calculated assuming that the individual entered welfare in the last period and has no previous benefit receipt history. The assumptions we make are thus favourable to finding both low predicted entry and persistence rates. All covariates are again kept fixed at their observed values.

The degree of state dependence in monthly benefit receipt rises substantially compared to that estimated for the standard Markov model in Table 1. The average predicted rate of entry into benefits drops from $1.4 \%$ to $0.3 \%$ as shown in column (1) of Table 4 . This likely reflects the favourable assumptions of no previous benefit spells and a maximum duration off benefits made when calculating predicted entry rates. The persistence rate rises from $14.0 \%$ to $37.3 \%$. The resulting ATE of benefit receipt in the previous period on the likelihood of benefit receipt in the current period rises from 12.6 percentage points in the standard Markov model to 37.0 percentage points in the DRCP with duration and occurrence dependence.

To illustrate the impact of unobserved heterogeneity on welfare entry and persistence, we report some additional parameters from our DRCP model in the bottom part of Table 4. As summarized in column (1), unobserved heterogeneity in the monthly model is nearly equally important for the process driving entries as for the process driving benefit persistence as implied by the estimates of $\sigma_{a_{0}}$ and $\sigma_{a_{1}}$, the standard deviations of the two individual-specific error components $a_{i}^{0}$ and $a_{i}^{1}$. The estimated correlation between the two error components, given by $\tau=0.78$, indicates that the two persistent components of the error term in the monthly model are highly but imperfectly correlated. Intuitively, we may thus think of each individual as having some unobserved ability or preferences $a_{i}^{1}$ related to (avoiding) persistence in welfare and an ability $a_{i}^{0}$ related to entries to welfare. Ignoring these differences leads to a downward bias in the estimated degree of state dependence in welfare benefit receipt.

Compared to the predicted transition rates presented in Table 4, the magnitude of estimated duration and occurrence dependence illustrated in Figures 3-4 is indeed substantial. While the average predicted entry rate for individuals with the maximum duration off benefits is only $0.3 \%$, it is about 7 percentage points higher for individuals in their first month off benefits as shown in Figure 3. Also the seemingly-modest occurrence-dependence effect of around 0.8 percentage points after a single previous spell shown in Figure 4 is sizeable if we consider that it permanently raises an individual's predicted entry rate into benefits from $0.3 \%$ to $1.1 \%$. For individuals on benefits, the 20 percentage-point drop in exit rates after ten months of benefit 
Table 4: Time aggregation in the DRCP model: Monthly to Annual

\begin{tabular}{|c|c|c|}
\hline & $(1)$ & $(2)$ \\
\hline & $\begin{array}{l}\text { Monthly } \\
\text { model }\end{array}$ & $\begin{array}{l}\text { Monthly-to-annual } \\
\text { time aggregations }\end{array}$ \\
\hline \multicolumn{3}{|l|}{ State dependence } \\
\hline Average predicted persistence rate (in \%) & $37.3(0.5)$ & $6.3(0.2)$ \\
\hline - Average predicted entry rate (in \%) & $0.3(0.0)$ & $1.3(0.1)$ \\
\hline$=$ Average treatment effect (in ppts) & $37.0(0.5)$ & $5.0(0.2)$ \\
\hline \multicolumn{3}{|l|}{ Unobserved heterogeneity } \\
\hline$\sigma_{a_{1}}$ & $0.32(0.01)$ & \\
\hline$\sigma_{a_{0}}$ & $0.35(0.01)$ & \\
\hline$\tau$ & $0.78(0.03)$ & \\
\hline \multicolumn{3}{|c|}{$\begin{array}{l}\text { Note: The monthly model in column (1) refers to the dynamic random-coefficients probit specifications in Equa- } \\
\text { tions (23)-(25) with occurrence and duration dependence estimated on monthly data. The monthly-to-annual time } \\
\text { aggregation results presented in column }(2) \text { were obtained by aggregating the transitions of the monthly model } \\
\text { to the annual level using the approach described in Section } 3.2 \text {. Standard errors in parentheses of columns }(1) \\
\text { to (3) were calculated using } 10 \text { bootstrap replications. Coefficient estimates for the two specifications presented } \\
\text { in columns }(1) \text { and }(2) \text { are reported in Table A.5 of the Appendix. Parameters } \sigma_{a_{0}} \text { and } \sigma_{a_{1}} \text { are the standard } \\
\text { deviations of } a_{i}^{0} \text { and } a_{i}^{1} \text {, respectively, while } \tau \text { is their correlation. }\end{array}$} \\
\hline
\end{tabular}

receipt implied by Figure 3 compares to an average predicted exit rate from benefits of $37 \%$ for an individual in the first month of the benefit spell. ${ }^{29}$

A consequence of the significant duration and occurrence dependence estimated for the DRCP model at the monthly level is moreover that unlike the standard Markov model, some state dependence persists if we use the estimation results to simulate benefit transitions over an entire year. In column (2) of Table 4, we report December-to-December transition probabilities obtained from aggregating up the monthly transition probabilities to the annual level: In the case of benefit receipt 12 months ago the likelihood of benefit receipt today is $6.3 \%$ compared to $1.3 \%$ conditional on non-receipt 12 months ago. The average treatment effect of benefit receipt 12 months ago on benefit receipt today is hence estimated at 5.0 percentage points.

To evaluate the time aggregation properties of the DRCP model, we would again like to test how these aggregated results from our model of monthly benefit dynamics compare to a corresponding model estimated on annualized data. The appropriate benchmark in this case would be an annual DRCP specification that includes the complete vector of duration and occurrence variables measured at the monthly level. Consistent estimation of such a model however is not straightforward. The endogenous duration and occurrence variables are no longer deterministic functions of the current and past values of the dependent variable, because the latter is now measured at the annual level. Even the extended Wooldridge approach proposed for the monthly model in Equation (25) will therefore no longer give consistent estimates at the annual level (see the discussion in the Appendix, Section A.1). ${ }^{30}$ The evaluation procedure

\footnotetext{
${ }^{29}$ Note that a comparison of ATEs for the occurrence and duration dummies with average predicted transition rates is only approximate: For calculating the ATEs of duration dummies we kept the values of all occurrence dummies fixed at their observed values (and vice versa). By contrast, when predicting entry and persistence rates, we assume a 'clean' benefit receipt history. The two calculations thus do not make identical assumptions on an individual's benefit receipt history, an aspect that might have an impact due to the non-linearity of the model.

${ }^{30}$ We have estimated annual models that include monthly measures of spell durations and occurrences with simulated data and find that they give heavily-biased predictions. This confirms that the inconsistency is not merely a theoretical concern.
} 
used previously for the simpler annual Markov models therefore does not readily extend to a specification with duration and occurrence variables measured at the monthly level.

We propose an alternative evaluation method as a specification check for our DRCP model with duration and occurrence dependence. The test builds on the idea that if the model does well at describing the true benefit receipt dynamics at the monthly level, benefit receipt sequences simulated from the model should be 'similar' to those produced by the true data-generating process. Indeed, the required 'similarity' of the simulated and the true data must hold for all characteristics of the two data sets. For instance, we should expect any other model - also one that is misspecified - to provide similar results when estimated on the two data sets provided that the model used to construct the simulated data is well-specified. Larger disparities in results between the two by contrast should be seen as evidence that the model does not well at replicating the true benefit dynamics.

Table 5: Specification tests of the monthly DRCP model on annual data

\begin{tabular}{|c|c|c|c|}
\hline & \multirow{3}{*}{$\begin{array}{c}\text { Annual DRCP } \\
\text { in Eqs (20)-(22) } \\
(1) \\
\text { Annualized } \\
\text { true data }\end{array}$} & \multicolumn{2}{|c|}{$\begin{array}{c}\text { Simulation-based } \\
\text { specification check }\end{array}$} \\
\hline & & $(2)$ & $(3)$ \\
\hline & & $\begin{array}{c}\text { Annualized data, } \\
\text { monthly DRCP } \\
\text { in Eqs }(23)-(25)\end{array}$ & $\begin{array}{c}\text { Annualized data, } \\
\text { monthly DRCP } \\
\text { in Eqs }(20)-(22)\end{array}$ \\
\hline Average predicted persistence rate (in \%) & $12.6(1.0)$ & $6.4(0.6)$ & $3.2(0.2)$ \\
\hline - Average predicted entry rate (in \%) & $2.1(0.1)$ & $2.2(0.1)$ & $2.6(0.1)$ \\
\hline$=$ Average treatment effect (in ppts) & $10.5(1.1)$ & $4.1(0.6)$ & $0.5(0.2)$ \\
\hline
\end{tabular}

Note: The annual model in column (1) refers to the dynamic random-coefficients probit (DRCP) specifications in Equations (20)-(22) estimated on annualized data. The estimates presented in column (2) were obtained by estimating the DRCP specification in Equations (20)-(22) using annualized data that were simulated based on the monthly DRCP model in Equations (23)-(25) with duration and occurrence dependence. The estimates presented in column (3) were obtained by estimating the DRCP specification in Equations (20)-(22) using annualized data that were simulated based on the monthly DRCP model in Equations (20)-(22). Standard errors in parentheses of column (1) were calculated using 10 bootstrap replications; predicted transition rates and standard errors in parentheses of columns (2)-(3) were calculated based on running the annual model on 10 simulated data sets.

As a specification test, we thus run a different model on the true data and the data simulated from the DRCP model with duration and occurrence dependence and compare the results. Specifically, we use the simpler annual first-order DRCP model without duration and occurrence dependence described in Equations (20)-(22) for this exercise. ${ }^{31}$ This allows us to produce results comparable to those obtained in the time aggregation tests carried out in earlier parts of our analysis. We start by simulating benefit receipt dynamics for each individual over a 12-month period based on the estimates from the monthly DRCP model with duration and occurrence dependence. This step is identical to the one employed in the simulation-based specification checks for the simpler models. We then estimate the first-order DRCP model on the annualized simulated data and compare estimates to those we got from running the same model on annualized true data. The results of the specification test are presented in Table 5 .

The monthly DRCP model with duration and occurrence dependence only partially succeeds

\footnotetext{
${ }^{31}$ Complete estimation results for this model are presented in the working paper version of this article (Bhuller et al., 2014).
} 
at predicting the monthly welfare benefit dynamics in Norway. The annual first-order DRCP model estimated on annualized true data predicts an average treatment effect of benefit receipt 12 months ago of 10.5 percentage points (column (1)). Estimating the same model on data simulated from the monthly DRCP model with duration and occurrence dependence, we obtain average predicted entry rates that are nearly $50 \%$ lower (column (2)). For an essentially unchanged average predicted entry rate, this implies a decline in the ATE to only 4.1 percentage points. Note that we are not very much interested here in the estimated level of state dependence per se, because we already know that the model without duration and occurrence dependence is misspecified. The difference between the levels of state dependence estimated from the firstorder DRCP model when run on true data and on data simulated from the model with duration and occurrence dependence however indicates that also our most complex model does not do very well at reproducing the true month-to-month benefit dynamics.

The DRCP model with duration and occurrence dependence nonetheless represents a substantial improvement over models without duration and occurrence dependence. Column (3) presents results obtained from estimating the annual first-order DRCP Markov model on data simulated from the monthly first-order DRCP model. The average predicted persistence rate is lower still, making the estimated ATE drop to 0.5 percentage points. While our preferred monthly DRCP model thus does not succeed at replicating the same level of estimated state dependence that is observed in the true data, it gets much closer to the benchmark result than the simpler model.

\section{Conclusion}

Dynamic discrete-choice models have been an important tool for the analysis of labour market dynamics and in particular the study of state dependence in benefit receipt. One central assumption of such models is that sequences of benefit receipt follow a standard Markov process: Conditional on the observed and unobserved characteristics of an individual the first lag of the dependent variable is sufficient for predicting the outcome. Such models are usually estimated on data with annual observations from administrative records or household surveys due to a lack of data with shorter observation intervals. The main parameter of interest is the average treatment effect of the lagged dependent variable, which is interpreted as capturing structural state dependence in benefit receipt.

In this paper, we showed that a standard Markov model gives highly inconsistent estimates of the degree of structural state dependence in welfare benefit dynamics in Norway. Based on monthly administrative data over the 16-year period 1993-2008, we estimated the same specification at the monthly, annual and biennial level and used the results to predict individuals' implied period-to-period transition matrices. Due to the Markov property of the model, these transition matrices can be aggregated up over time and thus be compared across specifications. Results indicate that the magnitude of estimated state dependence rises strongly with the level of time aggregation. The annual model grossly overestimates the degree of state dependence predicted by a corresponding model at the monthly level; state dependence estimated by a biennial model is even higher. This finding is robust to employing the 'benefit year' approach rather than the 'point-in-time' approach for defining the annual benefit receipt variable. 
We conclude that the standard dynamic random-effects probit model is misspecified and not suited for an analysis of structural state dependence in welfare benefit receipt in Norway. Our results might moreover be evidence that, more generally, the Markov assumption commonly made in studies of labour market dynamics is too crude a simplification. Estimates of structural state dependence derived from such models are likely to be driven by the choice of the observation interval. The results from such analyses should therefore be interpreted with caution.

In the second part of the paper, we illustrated that benefit dynamics in Norway are indeed much more complex than it is commonly allowed for in econometric modelling. We presented a generalization of the standard model along two important dimensions in the form of a more flexible dynamic random-coefficients probit (DRCP) model. First, this model allows the processes driving entries into benefits and persistence in benefit receipt to differ with an individual's observable and unobservable characteristics. Second, it accounts for duration and occurrence dependence in benefit receipt. We found that an individual's two individual-specific error components for the welfare entry and persistence process are positively but imperfectly correlated. The length of the current spell and the number of previous spells have a sizeable effect on the probability of benefit receipt. While there is substantial duration dependence in both entries and persistence in benefit receipt, the number of previous benefit spells affects only entry rates. The average predicted month-to-month persistence rate for first-time entrants is 37 percentage points higher than the average predicted entry rate for individuals who have never received benefits. Aggregated to the annual level, this corresponds to an average treatment effect of 5 percentage points. A simple simulation-based specification test shows that benefit receipt sequences produced by this model are still clearly distinguishable from those of the true data-generating process. The model however represents a notable improvement over the simpler models without duration and occurrence dependence.

Our findings suggest that much more complex models of benefit receipt dynamics may be needed for reliable estimates of state dependence in benefit receipt. We have shown that in Norwegian welfare benefit dynamics 'state dependence' arises from a combination of the simple intercept shift induced by the standard lagged dependent variable, disparities in the impact of observable and unobservable characteristics on entry and persistence probabilities, and the effect of time spent in the current state on the probability of future benefit receipt. Future work will have to seek ways of better describing these different dynamics possibly by combining and extending some of the approaches we have used. The existence of duration and occurrence dependence however implies that such work will likely have to be based on data with comparably short observation intervals that permit identification of individuals' benefit spells.

A methodological contribution of this article is finally that it offers an intuitive and simple test of the validity of the Markov assumption for cases where no data with short observation intervals are available. By aggregating up the predicted transition matrices obtained from firstorder Markov models for instance at the annual level and comparing them to the predictions of the corresponding benchmark model at the biennial level, authors will be able to quickly evaluate the reliability of their estimates of the level of structural state dependence. This specification test shall be useful for assessing the robustness of the results obtained from simple models of welfare benefit receipt dynamics or labour-market-state dynamics more broadly. 


\section{References}

Akay, A. (2012). Finite-Sample Comparison of Alternative Methods for Estimating Dynamic Panel Data Models. Journal of Applied Econometrics, 27(7), 1189-1204.

Andrén, T. \& Andrén, D. (2013). Never Give Up? The Persistence of Welfare Participation in Sweden. IZA Journal of European Labor Studies, 2(1), 1-21.

Arulampalam, W., Booth, A. L., \& Taylor, M. P. (2000). Unemployment Persistence. Oxford Economic Papers, 52, 24-50.

Arulampalam, W. \& Stewart, M. B. (2009). Simplified Implementation of the Heckman Estimator of the Dynamic Probit Model and a Comparison with Alternative Estimators. Oxford Bulletin of Economics and Statistics, 71(5), 659-681.

Bäckman, O. \& Bergmark, Å. (2011). Escaping Welfare? Social Assistance Dynamics in Sweden. Journal of European Social Policy, 21(5), 486-500.

Bergström, R. \& Edin, P. (1992). Time Aggregation and the Distributional Shape of Unemployment Duration. Journal of Applied Econometrics, 7(1), 5-30.

Bhuller, M., Brinch, C. N., \& Königs, S. (2014). Time Aggregation and State Dependence in Welfare Receipt. Statistics Norway Research Department Discussion Paper, 771.

Biewen, M. (2009). Measuring State Dependence in Individual Poverty Histories when there is Feedback to Employment Status and Household Composition. Journal of Applied Econometrics, 24 (7), 1095-1116.

Biewen, M. \& Steffes, S. (2010). Unemployment Persistence: Is there Evidence for Stigma Effects? Economics Letters, 106(3), 188-190.

Blank, R. M. (1989). Analyzing the Length of Welfare Spells. Journal of Public Economics, $39(3), 245-273$.

Bratsberg, B., Raaum, O., \& Røed, K. (2010). When Minority Labor Migrants Meet the Welfare State. Journal of Labor Economics, 28(3), 633-676.

Butler, J. S. \& Moffitt, R. (1982). A computationally efficient quadrature procedure for the one-factor multinomial probit model. Econometrica, 761-764.

Cappellari, L. \& Jenkins, S. P. (2004). Modelling Low Income Transitions. Journal of Applied Econometrics, 19, 593-610.

Cappellari, L. \& Jenkins, S. P. (2008a). The Dynamics of Social Assistance Receipt: Measurement and Modelling Issues, with an Application to Britain. OECD Social, Employment, and Migration Working Papers, $6 \%$.

Cappellari, L. \& Jenkins, S. P. (2008b). Transitions Between Unemployment and Low Pay. In S. W. Polachek \& K. Tatsiramos (Eds.), Research in Labor Economics: "Work, Earnings and other Aspects of the Employment Relation", Vol. 28 (pp. 57-79). Emerald Group Publishing Limited. 
Cappellari, L. \& Jenkins, S. P. (2009). The Dynamics of Social Assistance Benefit Receipt in Britain. IZA Discussion Papers, $445 \%$.

Chamberlain, G. (1980). Analysis of Covariance with Qualitative Data. The Review of Economic Studies, 47(1), 225-238.

Chay, K. Y., Hoynes, H., \& Hyslop, D. (1999). A Non-Experimental Analysis of "True" State Dependence in Monthly Welfare Participation Sequences. American Statistical Association, 1999 Proceedings of the Business and Economic Statistics Section, 9-17.

Chay, K. Y. \& Hyslop, D. R. (2014). Identification and Estimation of Dynamic Binary Response Panel Data Models: Empirical Evidence using Alternative Approaches. In S. Carcillo, H. Immervoll, S. P. Jenkins, S. Königs, \& K. Tatsiramos (Eds.), Research in Labor Economics: "Safety Nets and Benefit Dependence", Vol. 39. Emerald Group Publishing Limited.

Dahl, E. \& Lorentzen, T. (2003a). Dynamics of Social Assistance: the Norwegian Experience in Comparative Perspective. International Journal of Social Welfare, 12(4), 289-301.

Dahl, E. \& Lorentzen, T. (2003b). Explaining Exit to Work among Social Assistance Recipients in Norway: Heterogeneity or Dependency? European Sociological Review, 19(5), 519-536.

Ellwood, D. T. (1982). Teenage Unemployment: Permanent Scars or Temporary Blemishes? In R. B. Freeman \& D. A. Wise (Eds.), The Youth Labor Market Problem: Its Nature, Causes, and Consequences (pp. 349-390). University of Chicago Press.

Engle, R. F. \& Liu, T.-C. (1972). Effects of Aggregation over Time on Dynamic Characteristics of an Econometric Model. In B. G. Hickman (Ed.), Econometric Models of Cyclical Behavior (pp. 673-738). National Bureau of Economic Research, Columbia University Press.

Gong, X. (2004). Transition Patterns for the Welfare Reliance of Low Income Mothers in Australia. IZA Discussion Papers, $104 \%$.

Gregg, P. (2001). The Impact of Youth Unemployment on Adult Unemployment in the NCDS. The Economic Journal, 111(475), 626-653.

Hansen, H. (2009). The Dynamics of Social Assistance Recipiency: Empirical Evidence from Norway. European Sociological Review, 25(2), 215-231.

Hansen, J. \& Lofstrom, M. (2008). The Dynamics of Immigrant Welfare and Labor Market Behavior. Journal of Population Economics, 22(4), 941-970.

Hansen, J. \& Lofstrom, M. (2011). Immigrant-Native Differences in Welfare Participation: The Role of Entry and Exit Rates. Industrial Relations: A Journal of Economy and Society, 50(3), 412-442.

Hansen, J., Lofstrom, M., Liu, X., \& Zhang, X. (2014). State Dependence in Social Assistance Receipt in Canada. In S. Carcillo, H. Immervoll, S. P. Jenkins, S. Königs, \& K. Tatsiramos (Eds.), Research in Labor Economics: "Safety Nets and Benefit Dependence", Vol. 39. Emerald Group Publishing Limited. 
Heckman, J. J. (1978). Simple Statistical Models for Discrete Panel Data Developed and Applied to Test the Hypothesis of True State Dependence against the Hypothesis of Spurious State Dependence. Annales de l'INSEE, 30/31, 227-269.

Heckman, J. J. (1981a). Heterogeneity and state dependence. In S. Rosen (Ed.), Studies in Labor Markets (pp. 91-140). University of Chicago Press: Studies in Labor Markets.

Heckman, J. J. (1981b). The Incidental Parameters Problem and the Problem of Initial Conditions in Estimating a Discrete Time-Discrete Data Stochastic Process. In C. F. Manski \& D. McFadden (Eds.), Structural Analysis of Discrete Data with Econometric Applications (pp. 179-195). Cambridge: The MIT Press.

Heckman, J. J. \& Borjas, G. (1980). Does Unemployment Cause Future Unemployment? Definitions, Questions and Answers from a Continuous Time Model of Heterogeneity and State Dependence. Economica, 47(187), 247-283.

Heckman, J. J. \& Navarro, S. (2007). Dynamic Discrete Choice and Dynamic Treatment Effects. Journal of Econometrics, 136(2), 341-396.

Honoré, B. E. (1993). Identification Results for Duration Models with Multiple Spells. The Review of Economic Studies, 60(1), 241-246.

Hyslop, D. (1999). State Dependence, Serial Correlation and Heterogeneity in Intertemporal Labor Force Participation of Married Women. Econometrica, 67(6), 1255-1294.

Immervoll, H., Jenkins, S. P., \& Königs, S. (2014). Are Recipients of Social Assistance 'Benefit Dependent'? Measurement and Results for Selected Countries. OECD Social, Employment, and Migration Working Papers, 162.

Königs, S. (2014). State Dependence in Social Assistance Benefit Receipt in Germany Before and After the Hartz Reforms. In S. Carcillo, H. Immervoll, S. P. Jenkins, S. Königs, \& K. Tatsiramos (Eds.), Research in Labor Economics: "Safety Nets and Benefit Dependence", Vol. 39. Emerald Group Publishing Limited.

Lorentzen, T. (2010). Social Assistance Dynamics in Norway: A Sibling Study of Intergenerational Mobility. Stein Rokkan Centre for Social Studies Report, 3.

Lorentzen, T. \& Dahl, E. (2005). Active Labour Market Programmes in Norway: Are they Helpful for Social Assistance Recipients? Journal of European Social Policy, 15(1), 27-45.

Mercenier, J. \& Michel, P. (1994). A Criterion for Time Aggregation in Intertemporal Dynamic Models. Mathematical Programming, 64(1-3), 179-197.

Mood, C. (2013). Social Assistance Dynamics in Sweden: Duration Dependence and Heterogeneity. Social Science Research, 42(1), 120-139.

Mundlak, Y. (1978). On the Pooling of Time Series and Cross Section Data. Econometrica, 46(1), 69-85. 
Petersen, T. \& Koput, K. W. (1992). Time-Aggregation Bias in Hazard-Rate Models with Covariates. Sociological Methods \& Research, 21(1), 25-51.

Prowse, V. (2012). Modeling Employment Dynamics With State Dependence and Unobserved Heterogeneity. Journal of Business and Economic Statistics, 30(3), 411-431.

Rabe-Hesketh, S. \& Skrondal, A. (2013). Avoiding Biased Versions of Wooldridge's Simple Solution to the Initial Conditions Problem. Economics Letters, 120(2), 346-349.

Rabe-Hesketh, S., Skrondal, A., \& Pickles, A. (2005). Maximum Likelihood Estimation of Limited and Discrete Dependent Variable Models with Nested Random Effects. Journal of Econometrics, 128(2), 301-323.

Riphahn, R. T. \& Wunder, C. (2013). State Dependence in Welfare Receipt: Transitions Before and After a Reform. CESifo Working Paper, 4485.

Røed, K. \& Zhang, T. (2002). A Note on the Weibull Distribution and Time Aggregation Bias. Applied Economics Letters, 9(7), 469-472.

Sandefur, G. D. \& Cook, S. T. (1998). Permanent Exits from Public Assistance: The Impact of Duration, Family, and Work. Social Forces, 77(2), 763-787.

Schels, B. (2013). Persistence or Transition: Young Adults and Social Benefits in Germany. Journal of Youth Studies, 16(7), 1-20.

Stewart, M. B. (2007). The Interrelated Dynamics of Unemployment and Low-Wage Employment. Journal of Applied Econometrics, 22, 511-531.

Stewart, M. B. \& Swaffield, J. K. (1999). Low Pay Dynamics and Transition Probabilities. Economica, 66(261), 23-42.

Taylor, H. M. \& Karlin, S. (1998). An Introduction to Stochastic Modeling (3rd ed.). San Diego: Academic Press.

Tiao, G. C. \& Wei, W. S. (1976). Effect of Temporal Aggregation on the Dynamic Relationship of Two Time Series Variables. Biometrika, 63(3), 513-523.

Uhlendorff, A. (2006). From No Pay to Low Pay and Back Again? A Multi-State Model of Low Pay Dynamics. IZA Discussion Papers, 2482.

Van den Berg, G. J. (2001). Duration Models: Specification, Identification and Multiple Durations. In J. J. Heckman \& E. Leamer (Eds.), Handbook of Econometrics, Vol. 5 (pp. 33813460). Elsevier Science Publishers.

Wei, G. C. G. \& Tanner, M. A. (1990). A Monte Carlo Implementation of the EM Algorithm and the Poor Man's Data Augmentation Algorithms. Journal of the American Statistical Association, 85(411), 699-704. 
Wooldridge, J. M. (2000). A Framework for Estimating Dynamic, Unobserved Effects Panel Data Models with Possible Feedback to Future Explanatory Variables. Economics Letters, $68(3), 245-250$.

Wooldridge, J. M. (2001). Econometric Analysis of Cross Section and Panel Data. MIT Press.

Wooldridge, J. M. (2005). Simple Solutions to the Initial Conditions Problem in Dynamic, Nonlinear Panel Data Models with Unobserved Heterogeneity. Journal of Applied Econometrics, 20(1), 39-54.

Wunder, C. \& Riphahn, R. T. (2014). The Dynamics of Welfare Entry and Exit amongst Natives and Immigrants. Oxford Economic Papers, 66(2), 580-604. 


\section{Appendix}

\section{A.1 An extension of the standard Wooldridge approach}

The dynamic random-effects probit model with persistent unobserved heterogeneity suffers from an endogeneity problem due to the correlation of the lagged dependent variable with the timeinvariant individual-specific error component $\alpha_{i}$, as discussed in Section 3. This initial conditions problem is even more severe in the specifications estimated in Sections 4.3 and 5 that additionally include either higher-order lags or measures of spell duration and the number of previous benefit spells. These variables are all functions of past realizations of the dependent variable and therefore by construction do not satisfy the strict exogeneity assumption made for the covariates.

In the standard model, we use the approach introduced by Wooldridge (2005) to address the initial conditions problem by specifying a relationship between $\alpha_{i}$ and the outcome in the initial period $y_{i 0}$, which the model conditions on. We can extend this method to allow for feedback effects from $y_{i t}$ to the endogenous covariates (duration and occurrence variables or the higher-order lags) that we call $w_{i t}$, by employing an approach developed by Wooldridge (2000) for dealing more broadly with endogenous regressors in dynamic unobserved-effects models.

Using the product law for conditional densities, we decompose the joint density of $\left(y_{i t}, w_{i t}\right)$ as

$$
\begin{array}{r}
f\left(y_{i t}, w_{i t} \mid y_{i t-1}, w_{i t-1}, x_{i t-1}, \alpha_{i} ; \zeta\right)=f\left(y_{i t} \mid y_{i t-1}, w_{i t-1}, x_{i t-1}, \alpha_{i} ; \theta\right) \times \\
f\left(w_{i t} \mid y_{i t}, y_{i t-1}, w_{i t-1}, x_{i t-1}, \alpha_{i} ; \omega\right) .
\end{array}
$$

As in Section 3.1, the joint likelihood of the benefit receipt status and the set of endogenous covariates over all time periods follows as

$$
\begin{array}{r}
f\left(y_{i}, w_{i} \mid y_{i 0}, w_{i 0}, x_{i} ; \zeta\right)=\int \prod_{t=1}^{T} f\left(y_{i t} \mid y_{i t-1}, w_{i t-1}, x_{i t-1}, \alpha_{i} ; \theta\right) \times \\
f\left(w_{i t} \mid y_{i t}, y_{i t-1}, w_{i t-1}, x_{i t-1}, \alpha_{i} ; \omega\right) g\left(\alpha_{i} \mid y_{i 0}, w_{i 0}, x_{i} ; \gamma\right) d \alpha_{i},
\end{array}
$$

where $\left(y_{i 0}, w_{i 0}\right)$ are the initial-period values of the benefit receipt status and the endogenous covariates, respectively. This expression is the analogue of Equation (3) in the standard model. Since in our monthly models, the endogenous covariates $w_{i t}$ are deterministic functions of $y_{i t}$, $y_{i t-1}$, and $w_{i t-1}$, this joint distribution simplifies to

$$
f\left(y_{i}, w_{i} \mid y_{i 0}, w_{i 0}, x_{i} ; \zeta\right)=\int \prod_{t=1}^{T} f\left(y_{i t} \mid y_{i t-1}, w_{i t-1}, x_{i t-1}, \alpha_{i} ; \theta\right) g\left(\alpha_{i} \mid y_{i 0}, w_{i 0}, x_{i} ; \gamma\right) d \alpha_{i} .
$$

As in the simple case, we can use this joint density to consistently estimate the model under the assumption that the distribution $\alpha_{i} \mid y_{i 0}, w_{i 0}, x_{i}$ is conditionally normal with expectation linear in all arguments and constant variance. The likelihood function of our monthly specification with higher-order lags or duration and occurrence variables is hence similar to that of the standard random-effects probit model, where the initial values of the benefit variable $y_{i 0}$ and of the duration and occurrence variables $w_{i 0}$ and again a vector of the lags and leads of all 
time-varying exogenous covariates $x_{i}$ are included as additional regressors. As in the standard case, we replace $x_{i}$ by the vector of longitudinal averages $\bar{x}_{i}$.

Note however that this approach does not easily extend to the annual model counterpart to the monthly models in Section 5 that we might have wanted to use as a benchmark for the predictions of our monthly specifications. Here, $w_{i t}$ is no longer a deterministic function of $\left(y_{i t}, y_{i t-1}, w_{i t-1}\right)$, because our measures of spell durations and occurrences are based on monthly information whereas the the outcome variable $y_{i t}$ is now measured at the annual level. In the annual case, Equation (A.2) therefore cannot be simplified to give Equation (A.3) and the outlined approach does not lead to consistent estimates. 


\section{A.2 Detailed estimation results}

\begin{tabular}{|c|c|c|c|c|}
\hline \multirow{3}{*}{$\begin{array}{l}y_{(t-1)} \\
\text { individual characteristics }\end{array}$} & \multicolumn{2}{|c|}{ MONTHLY MODEL } & \multicolumn{2}{|c|}{ ANNUAL MODEL } \\
\hline & $1.845^{* * *}$ & $(0.006)$ & $0.824^{* * *}$ & $(0.022)$ \\
\hline & & & & \\
\hline female & $-0.179^{* * *}$ & $(0.018)$ & $-0.125^{* * *}$ & $(0.023)$ \\
\hline immigrant & $0.376^{* * *}$ & $(0.038)$ & $0.271^{* * *}$ & $(0.044)$ \\
\hline age & $-0.051^{* *}$ & $(0.023)$ & $0.188^{* * *}$ & $(0.065)$ \\
\hline $\operatorname{age}^{2}$ & 0.077 & $(0.048)$ & $-0.390 * * *$ & $(0.140)$ \\
\hline years of education & 0.011 & $(0.007)$ & $0.121^{* * *}$ & $(0.012)$ \\
\hline years of education ${ }^{2}$ & $-0.003^{* * *}$ & $(0.000)$ & $-0.013^{* * *}$ & $(0.001)$ \\
\hline \multicolumn{5}{|l|}{ household characteristics } \\
\hline single, with children & $-0.066^{* * *}$ & $(0.011)$ & $0.088^{* * *}$ & $(0.033)$ \\
\hline couple, no children & $-0.192^{* * *}$ & $(0.032)$ & $-0.177^{*}$ & $(0.106)$ \\
\hline couple, with children & $-0.213^{* * *}$ & $(0.014)$ & -0.055 & $(0.045)$ \\
\hline child aged 0-5 years & $-0.114^{* * *}$ & $(0.010)$ & $-0.154^{* * *}$ & $(0.030)$ \\
\hline household size & $0.042^{* * *}$ & $(0.004)$ & $0.048^{* * *}$ & $(0.013)$ \\
\hline \multicolumn{5}{|l|}{ spouse characteristics } \\
\hline immigrant & 0.014 & $(0.051)$ & -0.049 & $(0.128)$ \\
\hline age & -0.005 & $(0.005)$ & -0.006 & $(0.012)$ \\
\hline age $^{2}$ & 0.003 & $(0.011)$ & 0.010 & $(0.030)$ \\
\hline years of education & $0.052^{* * *}$ & $(0.013)$ & 0.048 & $(0.033)$ \\
\hline years of education ${ }^{2}$ & $-0.005^{* * *}$ & $(0.001)$ & $-0.005^{* *}$ & $(0.002)$ \\
\hline \multicolumn{5}{|l|}{ year dummies } \\
\hline 1995 & $0.174^{* * *}$ & $(0.061)$ & 0.015 & $(0.106)$ \\
\hline 1996 & $0.192^{* * *}$ & $(0.057)$ & 0.085 & $(0.099)$ \\
\hline 1997 & $0.187^{* * *}$ & $(0.054)$ & 0.059 & $(0.095)$ \\
\hline 1998 & $0.148^{* * *}$ & $(0.050)$ & -0.055 & $(0.092)$ \\
\hline 1999 & $0.079^{*}$ & $(0.047)$ & -0.057 & $(0.090)$ \\
\hline 2000 & $0.075^{*}$ & $(0.044)$ & -0.038 & $(0.087)$ \\
\hline 2001 & $0.070^{*}$ & $(0.041)$ & -0.031 & $(0.083)$ \\
\hline 2002 & $0.084^{* *}$ & $(0.038)$ & -0.007 & $(0.081)$ \\
\hline 2003 & $0.087 * *$ & $(0.035)$ & 0.043 & $(0.078)$ \\
\hline 2004 & $0.101^{* * *}$ & $(0.032)$ & 0.074 & $(0.076)$ \\
\hline 2005 & $0.079^{* * *}$ & $(0.030)$ & 0.037 & $(0.076)$ \\
\hline 2006 & $0.081^{* * *}$ & $(0.029)$ & 0.070 & $(0.075)$ \\
\hline 2007 & $0.067 * *$ & $(0.028)$ & 0.001 & $(0.076)$ \\
\hline 2008 & -0.013 & $(0.028)$ & -0.113 & $(0.081)$ \\
\hline \multicolumn{5}{|l|}{ Wooldridge controls } \\
\hline$y_{0}$ & $1.451^{* * *}$ & $(0.034)$ & $0.995^{* * *}$ & $(0.037)$ \\
\hline single, with children & $-0.206^{* * *}$ & $(0.044)$ & $-0.407^{* * *}$ & $(0.060)$ \\
\hline couple, no children & $-0.941^{* * *}$ & $(0.117)$ & $-1.206^{* * *}$ & $(0.192)$ \\
\hline couple, with children & $-0.977^{* * *}$ & $(0.054)$ & $-1.007 * * *$ & $(0.078)$ \\
\hline child aged $0-5$ years & $1.161^{* * *}$ & $(0.039)$ & $0.783^{* * *}$ & $(0.054)$ \\
\hline household size & $-0.042^{* * *}$ & $(0.014)$ & $-0.036^{*}$ & $(0.021)$ \\
\hline local unemployment rate & $4.456^{* * *}$ & $(0.770)$ & $3.203^{* * *}$ & $(1.200)$ \\
\hline local unemployment rate & $2.272^{* * *}$ & $(0.263)$ & $2.772^{* * *}$ & $(0.812)$ \\
\hline constant & $-2.101^{* * *}$ & $(0.279)$ & $-4.244^{* * *}$ & $(0.737)$ \\
\hline$\sigma_{a}$ & $0.999 * * *$ & $(0.010)$ & $0.782^{* * *}$ & $(0.016)$ \\
\hline$\rho$ & $0.499^{* * *}$ & $(0.005)$ & $0.379 * * *$ & $(0.010)$ \\
\hline log Likelihood & \multicolumn{2}{|c|}{$-173,477.470$} & \multicolumn{2}{|c|}{$-23,624.319$} \\
\hline
\end{tabular}

- continued on next page - 
Table A.1 - continued from previous page -

\begin{tabular}{lcc}
\hline \# of observations & $3,279,708$ & 272,878 \\
\# of individuals & 30,899 & 30,899 \\
\hline \hline$* \mathrm{p}<0.10, * * \mathrm{p}<0.05, * * * \mathrm{p}<0.01$ & \\
Note: standard errors in parentheses. The dependent variable measures \\
receipt of welfare benefits in a given month for the monthly model and in \\
December of the given year for the annual model. 'Wooldridge controls' \\
include the outcome variable in the initial period $y_{0}$ and longitudinal av- \\
erages of the remaining variables listed. age has been divided by 100 to \\
produce suitably-sized coefficient estimates. The relevant base categor- \\
ies are males, natives, singles without children, and households without a \\
child aged below 5 years.
\end{tabular}

Table A.1: The standard Markov specification, 'point-in-time' definition: Monthly and Annual model 


\begin{tabular}{|c|c|c|c|c|}
\hline \multirow[b]{2}{*}{$y_{(t-1)}$} & \multicolumn{2}{|c|}{ ANNUAL MODEL } & \multicolumn{2}{|c|}{ BIENNIAL MODEL } \\
\hline & $0.854^{* * *}$ & $(0.022)$ & 0.617 & $(0.041)$ \\
\hline \multicolumn{5}{|l|}{ individual characteristics } \\
\hline female & $-0.119 * * *$ & $(0.022)$ & -0.148 & $(0.028)$ \\
\hline immigrant & $0.266^{* * *}$ & $(0.042)$ & 0.310 & $(0.053)$ \\
\hline age & $0.199 * * *$ & $(0.064)$ & 0.375 & $(0.115)$ \\
\hline $\operatorname{age}^{2}$ & $-0.412^{* * *}$ & $(0.140)$ & -0.797 & $(0.256)$ \\
\hline years of education & $0.120^{* * *}$ & $(0.011)$ & 0.153 & $(0.015)$ \\
\hline years of education ${ }^{2}$ & $-0.013^{* * *}$ & $(0.001)$ & -0.016 & $(0.001)$ \\
\hline \multicolumn{5}{|l|}{ household characteristics } \\
\hline single, with children & $0.090 * * *$ & $(0.033)$ & $0.195^{* * *}$ & $(0.052)$ \\
\hline couple, no children & $-0.176^{*}$ & $(0.106)$ & -0.132 & $(0.160)$ \\
\hline couple, with children & -0.052 & $(0.045)$ & 0.071 & $(0.071)$ \\
\hline child aged 0-5 years & $-0.158^{* * *}$ & $(0.030)$ & 0.029 & $(0.047)$ \\
\hline household size & $0.047^{* * *}$ & $(0.013)$ & 0.018 & $(0.020)$ \\
\hline \multicolumn{5}{|l|}{ spouse characteristics } \\
\hline immigrant & -0.040 & $(0.126)$ & $-0.369^{*}$ & $(0.190)$ \\
\hline age & -0.006 & $(0.012)$ & 0.013 & $(0.018)$ \\
\hline $\operatorname{age}^{2}$ & 0.011 & $(0.029)$ & -0.014 & $(0.044)$ \\
\hline years of education & 0.052 & $(0.032)$ & 0.031 & $(0.048)$ \\
\hline years of education ${ }^{2}$ & $-0.005^{* *}$ & $(0.002)$ & -0.004 & $(0.003)$ \\
\hline \multicolumn{5}{|l|}{ year dummies } \\
\hline 1995 & 0.066 & $(0.052)$ & & \\
\hline 1996 & 0.043 & $(0.052)$ & & \\
\hline 1997 & -0.075 & $(0.055)$ & $-0.108^{*}$ & $(0.056)$ \\
\hline 1998 & -0.079 & $(0.059)$ & & \\
\hline 1999 & -0.061 & $(0.062)$ & $-0.151^{* *}$ & $(0.067)$ \\
\hline 2000 & -0.052 & $(0.061)$ & & \\
\hline 2001 & -0.027 & $(0.063)$ & -0.097 & $(0.069)$ \\
\hline 2002 & 0.020 & $(0.068)$ & & \\
\hline 2003 & 0.051 & $(0.069)$ & 0.003 & $(0.080)$ \\
\hline 2004 & 0.017 & $(0.072)$ & & \\
\hline 2005 & 0.050 & $(0.076)$ & -0.012 & $(0.082)$ \\
\hline 2006 & -0.021 & $(0.082)$ & & \\
\hline 2007 & -0.131 & $(0.092)$ & $-0.214^{* *}$ & $(0.098)$ \\
\hline 2008 & 0.135 & $(0.101)$ & & \\
\hline \multicolumn{5}{|l|}{ Wooldridge controls } \\
\hline$y_{0}$ & $0.949 * * *$ & $(0.036)$ & $0.891^{* * *}$ & $(0.051)$ \\
\hline single, with children & $-0.409^{* * *}$ & $(0.059)$ & $-0.550^{* * *}$ & $(0.079)$ \\
\hline couple, no children & $-1.200 * * *$ & $(0.189)$ & $-1.017^{* * *}$ & $(0.247)$ \\
\hline couple, with children & $-1.001^{* * *}$ & $(0.077)$ & $-1.098^{* * *}$ & $(0.104)$ \\
\hline child aged $0-5$ years & $0.764^{* * *}$ & $(0.053)$ & $0.488^{* * *}$ & $(0.072)$ \\
\hline household size & -0.031 & $(0.021)$ & 0.008 & $(0.028)$ \\
\hline local unempl. rate & $3.265^{* * *}$ & $(1.187)$ & $3.402^{* *}$ & $(1.546)$ \\
\hline local unempl. rate & $2.664^{* * *}$ & $(0.810)$ & 1.884 & $(1.234)$ \\
\hline constant & $-4.331^{* * *}$ & $(0.726)$ & $-6.181^{* * *}$ & $(1.268)$ \\
\hline$\sigma_{a}$ & $0.759^{* * *}$ & $(0.016)$ & $0.757^{* * *}$ & $(0.030)$ \\
\hline$\rho$ & $0.366^{* * *}$ & $(0.010)$ & $0.364^{* * *}$ & $(0.018)$ \\
\hline log Likelihood & \multicolumn{2}{|c|}{$-23,648.885$} & \multicolumn{2}{|c|}{$-11,295.134$} \\
\hline \# of observations & \multicolumn{2}{|c|}{272,641} & \multicolumn{2}{|c|}{121,027} \\
\hline \# of individuals & \multicolumn{2}{|c|}{30,719} & \multicolumn{2}{|c|}{30,719} \\
\hline
\end{tabular}

- continued on next page - 
$* \mathrm{p}<0.10, * * \mathrm{p}<0.05, * * * \mathrm{p}<0.01$

Note: standard errors in parentheses. The dependent variable measures receipt of welfare benefits in December of the given year for both the annual and biennial model. 'Wooldridge controls' include the outcome variable in the initial period $y_{0}$ and longitudinal averages of the remaining variables listed. $a g e^{2}$ has been divided by 100 to produce suitablysized coefficient estimates. The relevant base categories are males, natives, singles without children, and households without a child aged below 5 years.

Table A.2: The standard Markov specification, 'point-in-time' definition: Annual and Biennial model 


\begin{tabular}{|c|c|c|c|c|}
\hline \multirow{3}{*}{$\begin{array}{l}y_{(t-1)} \\
\text { individual characteristics }\end{array}$} & \multicolumn{2}{|c|}{ ANNUAL MODEL } & \multicolumn{2}{|c|}{ BIENNIAL MODEL } \\
\hline & $1.226^{* * *}$ & $(0.016)$ & $0.689 * * *$ & $(0.030)$ \\
\hline & & & & \\
\hline female & $-0.085^{* * *}$ & $(0.017)$ & $-0.065^{* * *}$ & $(0.023)$ \\
\hline immigrant & $0.227^{* * *}$ & $(0.035)$ & $0.205^{* * *}$ & $(0.048)$ \\
\hline age & $0.103^{* *}$ & $(0.058)$ & -0.107 & $(0.120)$ \\
\hline age $^{2}$ & $-0.237^{* *}$ & $(0.126)$ & 0.221 & $(0.262)$ \\
\hline years of education & $0.085^{* * *}$ & $(0.010)$ & $0.135^{* * *}$ & $(0.013)$ \\
\hline years of education ${ }^{2}$ & $-0.010^{* * *}$ & $(0.001)$ & $-0.015^{* * *}$ & $(0.001)$ \\
\hline \multicolumn{5}{|l|}{ household characteristics } \\
\hline single, with children & $0.129 * * *$ & $(0.027)$ & $0.104^{* *}$ & $(0.045)$ \\
\hline couple, no children & -0.080 & $(0.076)$ & 0.057 & $(0.120)$ \\
\hline couple, with children & 0.018 & $(0.037)$ & 0.012 & $(0.060)$ \\
\hline child aged 0-5 years & $-0.110^{* * *}$ & $(0.024)$ & -0.001 & $(0.040)$ \\
\hline household size & $0.031^{* * *}$ & $(0.011)$ & $0.045^{* *}$ & $(0.017)$ \\
\hline \multicolumn{5}{|l|}{ spouse characteristics } \\
\hline immigrant & -0.161 & $(0.100)$ & -0.148 & $(0.146)$ \\
\hline age & -0.000 & $(0.010)$ & 0.002 & $(0.014)$ \\
\hline $\operatorname{age}^{2}$ & 0.003 & $(0.024)$ & 0.003 & $(0.035)$ \\
\hline years of education & $0.073^{* * *}$ & $(0.026)$ & $0.093^{* *}$ & $(0.038)$ \\
\hline years of education ${ }^{2}$ & $-0.007^{* * *}$ & $(0.002)$ & $-0.009^{* * *}$ & $(0.002)$ \\
\hline \multicolumn{5}{|l|}{ year dummies } \\
\hline 1995 & 0.041 & $(0.046)$ & & \\
\hline 1996 & 0.051 & $(0.040)$ & & \\
\hline 1997 & 0.033 & $(0.044)$ & $-0.151^{* * *}$ & $(0.045)$ \\
\hline 1998 & $-0.081^{*}$ & $(0.046)$ & & \\
\hline 1999 & -0.032 & $(0.050)$ & $-0.131^{* *}$ & $(0.054)$ \\
\hline 2000 & -0.044 & $(0.047)$ & & \\
\hline 2001 & -0.023 & $(0.049)$ & $-0.122^{* *}$ & $(0.053)$ \\
\hline 2002 & -0.002 & $(0.053)$ & & \\
\hline 2003 & 0.047 & $(0.054)$ & -0.079 & $(0.059)$ \\
\hline 2004 & -0.035 & $(0.056)$ & & \\
\hline 2005 & -0.028 & $(0.060)$ & $-0.146^{* *}$ & $(0.066)$ \\
\hline 2006 & -0.046 & $(0.063)$ & & \\
\hline 2007 & -0.099 & $(0.078)$ & $-0.195^{* *}$ & $(0.085)$ \\
\hline 2008 & $0.140^{*}$ & $(0.078)$ & & \\
\hline \multicolumn{5}{|l|}{ Wooldridge controls } \\
\hline$y_{0}$ & $0.896^{* * *}$ & $(0.024)$ & $1.010^{* * *}$ & $(0.040)$ \\
\hline single, with children & $-0.340^{* * *}$ & $(0.047)$ & $-0.151^{* *}$ & $(0.066)$ \\
\hline couple, no children & $-0.977^{* * *}$ & $(0.136)$ & $-1.023^{* * *}$ & $(0.190)$ \\
\hline couple, with children & $-0.866^{* * *}$ & $(0.060)$ & $-0.661^{* * *}$ & $(0.087)$ \\
\hline child aged 0-5 years & $0.659^{* * *}$ & $(0.041)$ & $0.423^{* * *}$ & $(0.059)$ \\
\hline household size & -0.008 & $(0.016)$ & -0.021 & $(0.024)$ \\
\hline local unempl. rate & $2.475^{* * *}$ & $(0.920)$ & $2.886^{* *}$ & $(1.297)$ \\
\hline local unempl. rate & $3.474^{* * *}$ & $(0.645)$ & $1.699^{*}$ & $(1.005)$ \\
\hline constant & $-2.749 * * *$ & $(0.650)$ & -0.285 & $(1.355)$ \\
\hline$\sigma_{a}$ & $0.691^{* * *}$ & $(0.013)$ & $0.793^{* * *}$ & $(0.024)$ \\
\hline$\rho$ & $0.323^{* * *}$ & $(0.008)$ & $0.386^{* * *}$ & $(0.014)$ \\
\hline $\log$ Likelihood & \multicolumn{2}{|c|}{$-38,376.555$} & \multicolumn{2}{|c|}{$-18,199.340$} \\
\hline \# of observations & \multicolumn{2}{|c|}{246,753} & \multicolumn{2}{|c|}{108,089} \\
\hline \# of individuals & \multicolumn{2}{|c|}{30,576} & \multicolumn{2}{|c|}{30,576} \\
\hline
\end{tabular}

- continued on next page - 
$* \mathrm{p}<0.10, * * \mathrm{p}<0.05, * * * \mathrm{p}<0.01$

Note: standard errors in parentheses. The dependent variable measures receipt of welfare benefits at any time during the given one-year / two-year period for the annual and biennial model, respectively. 'Wooldridge controls' include the outcome variable in the initial period $y_{0}$ and longitudinal averages of the remaining variables listed. age $^{2}$ has been divided by 100 to produce suitably-sized coefficient estimates. The relevant base categories are males, natives, singles without children, and households without a child aged below 5 years.

Table A.3: The standard Markov specification, 'benefit year' definition: Annual and Biennial model 


\begin{tabular}{|c|c|c|}
\hline \multirow[b]{2}{*}{$y_{(t-1)}$} & \multicolumn{2}{|c|}{$\begin{array}{l}\text { MONTHLY MODEL WITH } \\
\text { HIGHER-ORDER LAGS }\end{array}$} \\
\hline & $1.402^{* * *}$ & $(0.007)$ \\
\hline \multicolumn{3}{|l|}{ higher-order lags } \\
\hline$y_{(t-2)}$ & $0.562^{* * *}$ & $(0.008)$ \\
\hline$y_{(t-3)}$ & $0.247^{* * *}$ & $(0.008)$ \\
\hline$y_{(t-4)}$ & $0.157 * * *$ & $(0.008)$ \\
\hline$y_{(t-5)}$ & $0.082^{* * *}$ & $(0.009)$ \\
\hline$y_{(t-6)}$ & $0.090 * * *$ & $(0.009)$ \\
\hline$y_{(t-7)}$ & $0.047^{* * *}$ & $(0.009)$ \\
\hline$y_{(t-8)}$ & $0.035^{* * *}$ & $(0.009)$ \\
\hline$y_{(t-9)}$ & $0.035^{* * *}$ & $(0.009)$ \\
\hline$y_{(t-10)}$ & $0.024^{* * *}$ & $(0.009)$ \\
\hline$y_{(t-11)}$ & $0.069 * * *$ & $(0.009)$ \\
\hline$y_{(t-12)}$ & $0.106^{* * *}$ & $(0.008)$ \\
\hline \multicolumn{3}{|l|}{ individual characteristics } \\
\hline female & $-0.110^{* * *}$ & $(0.014)$ \\
\hline immigrant & $0.183^{* * *}$ & $(0.029)$ \\
\hline age & $-0.046^{* *}$ & $(0.023)$ \\
\hline $\operatorname{age}^{2}$ & 0.079 & $(0.049)$ \\
\hline years of education & $0.041^{* * *}$ & $(0.006)$ \\
\hline years of education ${ }^{2}$ & $-0.005^{* * *}$ & $(0.000)$ \\
\hline \multicolumn{3}{|l|}{ household characteristics } \\
\hline single, with children & $-0.025^{* *}$ & $(0.011)$ \\
\hline couple, no children & $-0.140^{* * *}$ & $(0.033)$ \\
\hline couple, with children & $-0.165^{* * *}$ & $(0.015)$ \\
\hline child aged $0-5$ years & $-0.075^{* * *}$ & $(0.011)$ \\
\hline household size & $0.048^{* * *}$ & $(0.004)$ \\
\hline \multicolumn{3}{|l|}{ spouse characteristics } \\
\hline immigrant & 0.040 & $(0.051)$ \\
\hline age & -0.006 & $(0.005)$ \\
\hline $\operatorname{age}^{2}$ & 0.011 & $(0.011)$ \\
\hline years of education & $0.052^{* * *}$ & $(0.013)$ \\
\hline years of education ${ }^{2}$ & $-0.005^{* * *}$ & $(0.001)$ \\
\hline \multicolumn{3}{|l|}{ year dummies } \\
\hline 1995 & $0.107^{* *}$ & $(0.052)$ \\
\hline 1996 & $0.119^{* *}$ & $(0.048)$ \\
\hline 1997 & $0.115^{* *}$ & $(0.046)$ \\
\hline 1998 & $0.088^{* *}$ & $(0.043)$ \\
\hline 1999 & 0.051 & $(0.041)$ \\
\hline 2000 & 0.063 & $(0.039)$ \\
\hline 2001 & 0.056 & $(0.037)$ \\
\hline 2002 & $0.069 * *$ & $(0.035)$ \\
\hline 2003 & $0.071^{* *}$ & $(0.032)$ \\
\hline 2004 & $0.079 * *$ & $(0.031)$ \\
\hline 2005 & $0.060 * *$ & $(0.030)$ \\
\hline 2006 & $0.058^{* *}$ & $(0.029)$ \\
\hline 2007 & 0.041 & $(0.028)$ \\
\hline 2008 & -0.022 & $(0.029)$ \\
\hline \multicolumn{3}{|l|}{ Wooldridge controls } \\
\hline$y_{0}$ & $0.275^{* * *}$ & $(0.036)$ \\
\hline
\end{tabular}


Table A.4 - continued from previous page -

\begin{tabular}{ccc}
\hline & \multicolumn{2}{c}{ MONTHLY MODEL WITH } \\
& \multicolumn{2}{c}{ HIGHER-ORDER LAGS } \\
\hline$y_{1}$ & $0.229^{* * *}$ & $(0.039)$ \\
$y_{2}$ & $0.108^{* * *}$ & $(0.040)$ \\
$y_{3}$ & $0.087^{* *}$ & $(0.038)$ \\
$y_{4}$ & $0.158^{* * *}$ & $(0.036)$ \\
$y_{5}$ & $0.220^{* * *}$ & $(0.037)$ \\
$y_{6}$ & $0.133^{* * *}$ & $(0.039)$ \\
$y_{7}$ & 0.006 & $(0.042)$ \\
$y_{8}$ & $0.099^{* *}$ & $(0.044)$ \\
$y_{9}$ & $0.177^{* * *}$ & $(0.045)$ \\
$y_{10}$ & -0.016 & $(0.048)$ \\
$y_{11}$ & -0.048 & $(0.047)$ \\
single, with children & $-0.137^{* * *}$ & $(0.034)$ \\
couple, no children & $-0.689^{* * *}$ & $(0.092)$ \\
couple, with children & $-0.641^{* * *}$ & $(0.043)$ \\
child aged 0-5 years & $0.760^{* * *}$ & $(0.030)$ \\
household size & $-0.042^{* * *}$ & $(0.011)$ \\
local unemployment rate & $3.098^{* * *}$ & $(0.616)$ \\
local unemployment rate & $2.241^{* * *}$ & $(0.266)$ \\
constant & $-2.208^{* * *}$ & $(0.275)$ \\
\hline $\begin{array}{l}\sigma_{a} \\
\rho\end{array}$ log Likelihood & $0.702^{* * *}$ & $(0.008)$ \\
\hline of individuals & $0.330^{* * *}$ & $(0.005)$ \\
\hline \hline
\end{tabular}

$* \mathrm{p}<0.10, * * \mathrm{p}<0.05,{ }^{* * *} \mathrm{p}<0.01$

Note: standard errors in parentheses. The dependent variable measures receipt of welfare benefits in a given month for the monthly model and in December of the given year for the annual model. 'Wooldridge controls' include the outcome variable in the initial twelve periods $y_{0}$ to $y_{11}$ and longitudinal averages of the remaining variables listed. $a g e^{2}$ has been divided by 100 to produce suitably-sized coefficient estimates. The relevant base categories are males, natives, singles without children, and households without a child aged below 5 years.

Table A.4: The higher-order Markov specification: Monthly model 


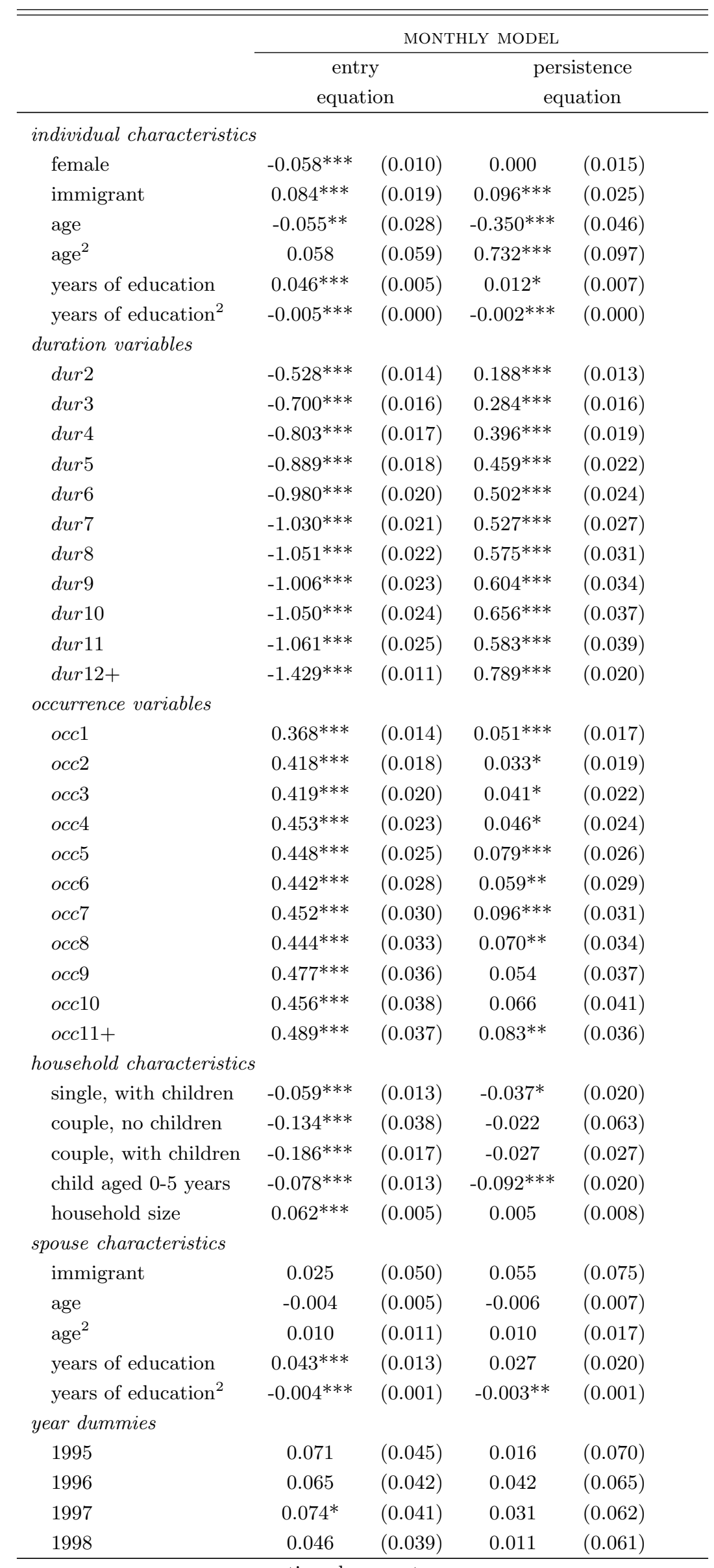

- continued on next page - 
Table A.5 - continued from previous page -

\begin{tabular}{|c|c|c|c|c|}
\hline \multirow[b]{3}{*}{1999} & \multicolumn{4}{|c|}{ MONTHLY MODEL } \\
\hline & \multicolumn{2}{|c|}{$\begin{array}{c}\text { entry } \\
\text { equation }\end{array}$} & \multicolumn{2}{|c|}{$\begin{array}{c}\text { persistence } \\
\text { equation }\end{array}$} \\
\hline & 0.011 & $(0.039)$ & -0.007 & $(0.060)$ \\
\hline 2000 & 0.030 & $(0.038)$ & 0.000 & $(0.058)$ \\
\hline 2001 & 0.027 & $(0.036)$ & 0.016 & $(0.056)$ \\
\hline 2002 & $0.059^{*}$ & $(0.035)$ & 0.005 & $(0.055)$ \\
\hline 2003 & $0.060^{*}$ & $(0.034)$ & 0.015 & $(0.053)$ \\
\hline 2004 & $0.086^{* *}$ & $(0.034)$ & -0.007 & $(0.053)$ \\
\hline 2005 & $0.072^{* *}$ & $(0.033)$ & -0.022 & $(0.052)$ \\
\hline 2006 & $0.058^{*}$ & $(0.033)$ & 0.020 & $(0.052)$ \\
\hline 2007 & 0.028 & $(0.034)$ & 0.040 & $(0.052)$ \\
\hline 2008 & -0.039 & $(0.036)$ & 0.003 & $(0.055)$ \\
\hline \multicolumn{5}{|l|}{ Wooldridge controls } \\
\hline$y_{11}$ & 0.010 & $(0.039)$ & -0.015 & $(0.042)$ \\
\hline single, with children & -0.017 & $(0.026)$ & $-0.069 *$ & $(0.037)$ \\
\hline couple, no children & $-0.454^{* * *}$ & $(0.070)$ & -0.152 & $(0.108)$ \\
\hline couple, with children & $-0.277^{* * *}$ & $(0.033)$ & $-0.199 * * *$ & $(0.051)$ \\
\hline child, aged 0-5 years & $0.382^{* * *}$ & $(0.024)$ & $0.141^{* * *}$ & $(0.035)$ \\
\hline household size & $-0.057 * * *$ & $(0.009)$ & -0.008 & $(0.014)$ \\
\hline local unempl. rate & $1.391^{* * *}$ & $(0.503)$ & $-1.677^{* *}$ & $(0.797)$ \\
\hline$d u r 2_{11}$ & -0.011 & $(0.043)$ & -0.047 & $(0.048)$ \\
\hline $\operatorname{dur} 2_{11} * y_{11}$ & 0.055 & $(0.060)$ & 0.088 & $(0.065)$ \\
\hline$d u r 3_{11}$ & $-0.075^{*}$ & $(0.041)$ & -0.058 & $(0.047)$ \\
\hline $\operatorname{dur} 3_{11} * y_{11}$ & $0.209^{* * *}$ & $(0.064)$ & 0.075 & $(0.069)$ \\
\hline$d u r 4_{11}$ & $-0.116^{* * *}$ & $(0.039)$ & $-0.108^{* *}$ & $(0.045)$ \\
\hline$d u r 4_{11} * y_{11}$ & $0.289^{* * *}$ & $(0.064)$ & $0.293^{* * *}$ & $(0.067)$ \\
\hline$d u r 5_{11}$ & -0.048 & $(0.043)$ & $-0.083^{*}$ & $(0.050)$ \\
\hline$d u r 5_{11} * y_{11}$ & 0.117 & $(0.077)$ & $0.263^{* * *}$ & $(0.081)$ \\
\hline$d u r 6_{11}$ & $-0.154^{* * *}$ & $(0.052)$ & $-0.221^{* * *}$ & $(0.066)$ \\
\hline $\operatorname{dur} 6_{11} * y_{11}$ & $0.234^{* * *}$ & $(0.082)$ & $0.327 * * *$ & $(0.092)$ \\
\hline$d u r 7_{11}$ & $-0.172^{* * *}$ & $(0.066)$ & $-0.216^{* * *}$ & $(0.084)$ \\
\hline$d u r 7_{11} * y_{11}$ & $0.185^{*}$ & $(0.098)$ & $0.329^{* * *}$ & $(0.110)$ \\
\hline$d u r 8_{11}$ & $-0.113^{*}$ & $(0.066)$ & -0.016 & $(0.079)$ \\
\hline $\operatorname{dur} 8_{11} * y_{11}$ & $0.330^{* * *}$ & $(0.108)$ & $0.219 *$ & $(0.115)$ \\
\hline$d u r 9_{11}$ & -0.085 & $(0.071)$ & $-0.285^{* * *}$ & $(0.092)$ \\
\hline$d u r 9_{11} * y_{11}$ & $0.360^{* * *}$ & $(0.119)$ & $0.546^{* * *}$ & $(0.129)$ \\
\hline$d u r 10_{11}$ & -0.128 & $(0.093)$ & $-0.224^{*}$ & $(0.126)$ \\
\hline $\operatorname{dur} 10_{11} * y_{11}$ & $0.267^{* *}$ & $(0.125)$ & $0.519^{* * *}$ & $(0.151)$ \\
\hline dur $11_{11}$ & $-0.311^{* * *}$ & $(0.111)$ & -0.087 & $(0.156)$ \\
\hline$d u r 11_{11} * y_{11}$ & $0.553^{* * *}$ & $(0.138)$ & 0.239 & $(0.176)$ \\
\hline$d u r 12+{ }_{11}$ & $-0.268^{* * *}$ & $(0.043)$ & $-0.227^{* * *}$ & $(0.045)$ \\
\hline$d u r 12+{ }_{11} * y_{11}$ & $0.523^{* * *}$ & $(0.059)$ & $0.579^{* * *}$ & $(0.058)$ \\
\hline$o c c 1_{11}$ & 0.022 & $(0.031)$ & 0.021 & $(0.032)$ \\
\hline occ $2_{11}$ & $0.089 * *$ & $(0.036)$ & 0.061 & $(0.038)$ \\
\hline$o c c 3_{11}$ & $0.161^{* * *}$ & $(0.050)$ & 0.054 & $(0.052)$ \\
\hline$o c c 4_{11}$ & $0.185^{*}$ & $(0.097)$ & 0.003 & $(0.102)$ \\
\hline local unempl. rate & $1.613^{* * *}$ & $(0.311)$ & $2.694^{* * *}$ & $(0.501)$ \\
\hline constant & -0.114 & $(0.324)$ & $4.283^{* * *}$ & $(0.531)$ \\
\hline$\sigma_{a}$ & $0.354^{* * *}$ & $(0.010)$ & $0.319^{* * *}$ & $(0.009)$ \\
\hline
\end{tabular}


Table A.5 - continued from previous page -

\begin{tabular}{|c|c|c|c|c|}
\hline & \multicolumn{4}{|c|}{ MONTHLY MODEL } \\
\hline & \multicolumn{2}{|c|}{$\begin{array}{c}\text { entry } \\
\text { equation }\end{array}$} & \multicolumn{2}{|c|}{$\begin{array}{c}\text { persistence } \\
\text { equation }\end{array}$} \\
\hline$\rho$ & $0.111^{* * *}$ & $(0.006)$ & $0.092^{* * *}$ & $(0.005)$ \\
\hline$\tau$ & \multicolumn{4}{|c|}{$0.784^{* * *} \quad(0.026)$} \\
\hline log Likelihood & \multicolumn{4}{|c|}{$-158,370.707$} \\
\hline \# of observations & \multicolumn{4}{|c|}{$3,279,708$} \\
\hline \# of individuals & \multicolumn{4}{|c|}{30,899} \\
\hline
\end{tabular}

$* \mathrm{p}<0.10, * * \mathrm{p}<0.05, * * * \mathrm{p}<0.01$

Note: standard errors in parentheses. The dependent variable measures receipt of SEA benefits in a given month for the monthly model and in December of the given year for the annual model. The variables labelled $d u r *$ and $o c c *$ are dummy variables measuring the duration of the ongoing spell and the number of previous spells, respectively. 'Wooldridge controls' include the outcome variable in the initial period $y_{11}$ and longitudinal averages of the time-varying variables, as well as the values of the duration and occurrence dummies in the initial period and their interactions with outcome variable in the initial period. $a g e^{2}$ has been divided by 100 to produce suitably-sized coefficient estimates. The relevant base categories are males, natives, singles without children, and households without a child aged below 5 years. Parameters $\sigma_{a}$ in the entry and the persistence equation are the standard deviations of the individual-specific random effects $\alpha_{i}^{0}$ and $\alpha_{i}^{1}$ as specified in Equations (23)-(24), respectively, while $\tau$ is their correlation.

Table A.5: The DRCP specification with duration and occurrence dependence: Monthly model 